\title{
The ASSET intercomparison of stratosphere and lower mesosphere humidity analyses
}

\author{
H. E. Thornton ${ }^{1}$, D. R. Jackson ${ }^{1}$, S. Bekki ${ }^{2}$, N. Bormann ${ }^{3}$, Q. Errera ${ }^{4}$, A. J. Geer ${ }^{3}$, W. A. Lahoz ${ }^{5}$, and S. Rharmili ${ }^{2}$ \\ ${ }^{1}$ Met Office, UK \\ ${ }^{2}$ UPMC Univ Paris 06; CNRS; SA-IPSL, France \\ ${ }^{3}$ European Centre for Medium-Range Weather Forecasts, UK \\ ${ }^{4}$ Insitut d'Aéronomie Spatiale de Begique, BIRA-IASB, Belgium \\ ${ }^{5}$ Norsk Institutt for Luftforskning, Norway
}

Received: 8 April 2008 - Published in Atmos. Chem. Phys. Discuss.: 15 July 2008

Revised: 6 January 2009 - Accepted: 6 January 2009 - Published: 9 February 2009

\begin{abstract}
This paper presents results from the first detailed intercomparison of stratosphere-lower mesosphere water vapour analyses; it builds on earlier results from the EU funded framework V "Assimilation of ENVISAT Data" (ASSET) project. Stratospheric water vapour plays an important role in many key atmospheric processes and therefore an improved understanding of its daily variability is desirable. With the availability of high resolution, good quality Michelson Interferometer for Passive Atmospheric Sounding (MIPAS) water vapour profiles, the ability of four different atmospheric models to assimilate these data is tested. MIPAS data have been assimilated over September 2003 into the models of the European Centre for Medium Range Weather Forecasts (ECMWF), the Belgian Institute for Space and Aeronomy (BIRA-IASB), the French Service d'Aéronomie (SA-IPSL) and the UK Met Office. The resultant middle atmosphere humidity analyses are compared against independent satellite data from the Halogen Occultation Experiment (HALOE), the Polar Ozone and Aerosol Measurement (POAM III) and the Stratospheric Aerosol and Gas Experiment (SAGE II). The MIPAS water vapour profiles are generally well assimilated in the ECMWF, BIRA-IASB and SA systems, producing stratosphere-mesosphere water vapour fields where the main features compare favourably with the independent observations. However, the models are less capable of assimilating the MIPAS data where water vapour values are locally extreme or in regions of strong humidity gradients, such as the southern hemisphere lower stratosphere polar vortex. Differences in the analyses can be attributed to the choice of humidity control variable, how the background error covariance matrix is generated, the model
\end{abstract}

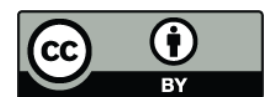

Correspondence to: H. E. Thornton (hazel.thornton@metoffice.gov.uk) resolution and its complexity, the degree of quality control of the observations and the use of observations near the model boundaries. Due to the poor performance of the Met Office analyses the results are not included in the intercomparison, but are discussed separately. The Met Office results highlight the pitfalls in humidity assimilation, and provide lessons that should be learnt by developers of stratospheric humidity assimilation systems. In particular, they underline the importance of the background error covariances in generating a realistic troposphere to mesosphere water vapour analysis.

\section{Introduction}

The "Assimilation of ENVISAT Data" project (ASSET: http://darc.nerc.ac.uk/asset/; Lahoz et al., 2007) was an EU funded initiative to exploit and develop earth observation data from ENVISAT using data assimilation. ENVISAT was launched in 2002 and is one of the largest Earth Observation (EO) satellites ever built. It carries several sophisticated EO instruments providing insights into the chemistry and dynamics of the atmosphere. ASSET has co-ordinated the assimilation of different ENVISAT data products into a variety of different atmospheric models, both global circulation models (GCMs) and chemical transport models (CTMs). The resultant analyses therefore can be used to study constituent atmospheric variability and modelling differences. Stratospheric water vapour analyses have been produced by a number of centres within the ASSET project. This paper summarises the differences between the water vapour analyses and how they compare with independent observations. The aim is to summarise the current performance of humidity assimilation schemes, highlighting areas where improvement is required, and quantifying their errors.

Published by Copernicus Publications on behalf of the European Geosciences Union. 
Gaining a good knowledge of the daily variability of the water vapour field in the stratosphere is very desirable, as upper troposphere/lower stratosphere (UTLS) water vapour is known to play an important role in many aspects of meteorology, including radiation, dynamics, chemistry and climate change (Kley et al., 2000). For example, water vapour is the main source of the hydrogen radicals which are responsible for most of the ozone destruction in the lower stratosphere and it is also a major greenhouse gas in the UTLS. A detailed understanding of the characterisation of the water vapour field and its variability in the UTLS region would also improve our understanding of cirrus clouds and the identification of the transport pathways between the troposphere and the stratosphere, in particular the relative importance of slow tropical ascent and of deep convection. Our observational knowledge of this daily variability remains relatively poor. Brewer (1949) first reported the extreme dryness of stratospheric air via aircraft-borne hygrometer observations, but these observations were only made over southern England. In subsequent decades the observational knowledge of stratospheric water vapour was extended, using balloon-borne frost point hygrometer (e.g. Mastenbrook and Daniels, 1980) and Lyman-alpha hygrometer (e.g. Kley et al., 1979) observations, but these were also only available at a small number of geographical locations. These observations showed that water vapour increased with height in the stratosphere and that a water vapour minimum (the hygropause) existed 2$3 \mathrm{~km}$ above the tropopause (e.g. Kley et al., 1979).

The first global observations of stratospheric water vapour were made by the Limb Infrared Monitor of the Stratosphere (LIMS) satellite instrument in 1978. These observations provided extended latitudinal coverage $\left(64^{\circ} \mathrm{S}-84^{\circ} \mathrm{N}\right)$, confirmed the earlier in-situ hygrometer observations and showed that the hygropause was a general feature of the tropical stratosphere. Subsequently, observations from the Upper Atmosphere Research Satellite (UARS) launched in 1991, including measurements from the Microwave Limb Sounder (MLS), Cryogenic Limb Array Etalon Spectrometer (CLAES) and the Improved Stratospheric and Mesospheric Sounder (ISAMS), made a further important contribution to the observational knowledge of stratospheric water vapour (e.g. Pumphrey et al., 1998). These data were only available for relatively short time periods (6-18 months), but observations of longer-term stratospheric water vapour variability are available from other instruments such as the Halogen Occultation Experiment (HALOE), the Stratospheric Aerosol and Gas Experiment (SAGE II) and the Polar Ozone and Aerosol Measurement experiments (POAM II \& III). A particularly important result was reported by Mote et al. (1996), who used HALOE observations to show the influence of tropical tropopause temperatures and stratospheric transport on the equatorial stratospheric water vapour distribution (also known as the "tropical tape recorder").

Data assimilation is a highly effective method of representing and understanding the daily variability of meteoro- logical fields (Kalnay, 2003). However, the application of data assimilation to stratospheric water vapour has hitherto been limited by either the lack of reliable humidity data or the lack of well-tested assimilation setups using such data. LIMS and UARS/MLS humidity data were available before humidity assimilation methods became sufficiently well developed, and therefore these data were never, to our knowledge, assimilated. The SAGE II and HALOE instruments use solar occultation and therefore have very poor daily spatial sampling of the atmosphere. Therefore, the assimilation of these humidity data would be of minimal use. Currently, the operational assimilation of humidity data in the stratosphere by Numerical Weather Prediction (NWP) centres is limited by the availability of suitable data (Simmons et al., 1999). For example, the quality of humidity observations from radiosondes decreases with decreasing water vapour and thus stratospheric water vapour observations from radiosondes are not very useful (Schmidlin and Ivanov, 1998), whilst operational satellite sounders tend to be only sensitive to tropospheric water vapour (e.g. the Advanced TIROS Operational Sounder, ATOVS) or total water vapour column (e.g. the Special Sensor Microwave/Imager, SSM/I). An additional handicap to the development of an effective stratospheric water vapour assimilation system is the reduction in specific humidity by four to five orders of magnitude (in volume mixing ratio units) from the surface to $0.1 \mathrm{hPa}$, making the assimilation problem considerably more difficult. Due to these difficulties, the Met Office (N. B. Ingleby, personal commmunication, 2003) and ECMWF (Hólm et al., 2002) have made until recently ad hoc fixes to constrain the stratospheric humidity field.

However, with the availability of high quality humidity data from ENVISAT with high spatial and temporal density (see, e.g. Raspollini et al., 2006), it is now appropriate to revisit the issue of stratospheric humidity assimilation. Here we present detailed results from the assimilation of Michelson Interferometer for Passive Atmospheric Sounding (MIPAS) humidity profiles into four different data assimilation (DA) systems; (European Centre for Medium-range Weather Forecasts, ECMWF; UK Met Office; Belgian Institute of Space Aeronomy, BIRA-IASB; Service d'Aéronomie - Institut Pierre Simon Laplace, SA-IPSL). This builds on the preliminary results reported by Lahoz et al. (2007). Validated MIPAS data were not available in real-time and therefore could not be assimilated operationally, rather it has been assimilated, once available, for research. A summary of the quality of MIPAS data is given in Sect. 3. The period of intercomparison is 29 August 2003-29 September 2003. To our knowledge, this is the first detailed study to perform such a comparison. This humidity intercomparison is carried out following the same methodology as the ASSET intercomparison of ozone analyses (Geer et al., 2006).

The ECMWF and Met Office systems are based on a troposphere-stratosphere GCM; the BIRA-IASB and SAIPSL systems are based on stratospheric CTMs. The 
BIRA-IASB system is the Belgian Assimilation System of Chemical Observations from ENVISAT (BASCOE); the SA system is the Assimilation system based on the Modele Isentrope de transport Mesoechelle de l'Ozone Stratospherique par Advection (MIMOSA-ASSI). The Met Office results were much poorer than those from the other groups, and are not included in the intercomparison, but rather discussed separately.

Section 2 describes the DA systems from ECMWF, BIRAIASB and SA-IPSL; the Met Office system is discussed in Sect. 6. The independent humidity datasets against which the analyses are compared: HALOE, SAGE II and POAM III, along with the UARS data used as climatology, are described in Sect. 3. Section 4 describes the intercomparison methodology. The results from the intercomparison are discussed in Sect. 5. The Met Office results are summarized in Sect. 6, to highlight the difficulties that still exist in developing stratospheric humidity assimilation systems, outlining the lessons that need to be learnt by future developers. Finally, Sect. 7 presents conclusions.

\section{Assimilation systems}

This section describes the different DA schemes used in the study. MIPAS data, as described in Sect. 3.1, were assimilated in all the assimilation systems. The selection of MIPAS data for each experiment was not identical, but depended on the quality control procedure used in each system.

\subsection{ECMWF}

Analyses were performed with an experimental version of the ECMWF 4D-Var system (Rabier et al., 2000) which was run for the 43 day period covering 18 August 200329 September 2003. The assimilation scheme was incremental 4D-Var with a 12-h cycle. The model horizontal resolution is T511 $(\sim 40 \mathrm{~km})$, but the assimilation is carried out at a horizontal resolution of T159 $(\sim 125 \mathrm{~km})$. There are 60 levels in the vertical up to $0.1 \mathrm{hPa}$. The model is a GCM in which humidity is advected using a semi-lagrangian transport scheme. Simple parametrizations account for the stratospheric water vapour source due to methane oxidation and for the mesospheric water vapour sink due to hydrogen photolysis.

The system was based on that used operationally in autumn 2005, with important modifications as follows. For the analyses described in this paper, the experimental stratospheric humidity analysis was activated, following the work of Hólm et al. (2002). This is in contrast to the current operational practice of suppressing humidity increments in the stratosphere, and we report here on some of the first experiences with such stratospheric humidity analyses. The humidity control variable was normalised relative humidity, reducing to normalised specific humidity in the stratosphere. The formulation of the background errors, was that used operationally in 2003 for all variables, and was generated using the ensemble method (Fisher, 2003). The assimilation of Global Positioning System Radio Occultation (GPSRO) bending angles was included, given the ability of the data to correct temperature biases in the analyses for the UTLS region (Healy and Thépaut, 2006). Other observations included the usual set of conventional and aircraft observations, clear-sky radiances from the ATOVS instruments, AIRS, SSMI, and geostationary satellites, Atmospheric Motion Vectors from geostationary and polar satellites, scatterometer data, as well as ozone retrievals from the SBUV instrument onboard NOAA16. All of these observations show little or no sensitivity to stratospheric humidity.

In addition, MIPAS reprocessed humidity, temperature and ozone retrievals (version 4.61, hereafter v4.61; Raspollini et al., 2006) were assimilated. For humidity and ozone, profiles of partial columns were used. Quality control was based on a check against the background field to remove gross outliers (i.e. data that deviates from the background by more than six times the expected deviation), followed by variational quality control (Andersson and Järvinen, 1999). The experiment used in this intercomparison is the same as the "RETR" experiment discussed in Bormann et al. (2007) in the comparison with results from a direct assimilation of MIPAS limb radiances into the ECMWF system.

\subsection{BASCOE}

BASCOE is a 4D-Var assimilation system described in Errera et al. (2008). This system is based on a 3-D CTM with interactive stratospheric chemistry using a time step of 30 min. The CTM is driven by ECMWF operational analyses of winds and temperatures, and uses a subset of 37 of the ECMWF model levels, from the surface to $0.1 \mathrm{hPa}$, on a $5^{\circ}$ longitude by $3.75^{\circ}$ latitude grid. The BASCOE CTM includes a parametrization to take into account the effect of Polar Stratospheric Clouds (PSCs), namely:

1. the ozone loss due to chlorine activation, and

2. the loss of $\mathrm{H}_{2} \mathrm{O}$ and $\mathrm{HNO}_{3}$ due to PSC sedimentation.

The latter parametrization is very simple and has the following form; at grid points where nitric acid trihydrate (NAT) is present, $\mathrm{HNO}_{3}$ decays with a characteristic time-scale of 100 days, while at grid points where ice particles are present, $\mathrm{H}_{2} \mathrm{O}$ and $\mathrm{HNO}_{3}$ decay with a timescale of 9 days (Solomon and Brasseur, 1997). NAT particles are assumed to exist polewards of $50^{\circ} \mathrm{S}$, between the tropopause and $10 \mathrm{hPa}$, when the temperature drops below $194^{\circ} \mathrm{K}$. If the temperature falls below $186^{\circ} \mathrm{K}$, ice particles are assumed to exist in place of NAT particles. In contrast to the ECWMF and Met Office data assimilation systems, humidity photolysis and methane oxidation are modelled explicitly in the BASCOE system.

Although the BASCOE model extends down to the surface, it does not include any tropospheric processes. In order 
to improve the lower stratospheric humidity field, it is necessary to have a realistic lower boundary. In this study, BAS$\mathrm{COE}$ tropospheric water vapour values are therefore replaced by operational ECWMF humidity analysis values which have been interpolated onto the BASCOE grid. Consequently below the tropopause, the assimilation of MIPAS profiles does not affect the resultant analysis field.

MIPAS v4.61 ozone $\left(\mathrm{O}_{3}\right)$, water vapour $\left(\mathrm{H}_{2} \mathrm{O}\right)$, nitric acid $\left(\mathrm{HNO}_{3}\right)$, nitrogen dioxide $\left(\mathrm{NO}_{2}\right)$, methane $\left(\mathrm{CH}_{4}\right)$ and nitrous oxide $\left(\mathrm{N}_{2} \mathrm{O}\right)$ are assimilated over a 24 hour window as described in Errera et al. (2008). Water vapour is a control variable in the BASCOE 4D-VAR system and the background errors are diagonal (i.e. all off-diagonal elements are set to zero) with a standard deviation equal to $20 \%$ of the background humidity field. Increments are spread in the horizontal due to the observation operator averaging points in and around the grid point in question. There are no crosscorrelations between different analysis variables (see also the discussion in Errera et al. (2008), Sect. 4). Finally, BASCOE includes a simple data filter, MIPAS data are rejected if the observed values deviate from the background by more than three times the background error.

\subsection{MIMOSA-ASSI}

In this study, MIPAS water vapour v4.61 measurements were assimilated. It is worth pointing out that there is no on-line filtering of the MIPAS data (e.g. no rejection of data on the basis of the difference with the forecast) and therefore outliers in the data can produce discontinuities in the analysis. The MIMOSA-ASSI system is a sub-optimal Kalman filter (KF) designed for assimilating long lived stratospheric species. MIMOSA is a high-resolution transport model that uses isentropic vertical coordinates with 16 levels between $450 \mathrm{~K}(\sim 50 \mathrm{hPa})$ and $1380 \mathrm{~K}(\sim 5 \mathrm{hPa})$. The model horizontal resolution used for this study is $1^{\circ}$ latitude by $1^{\circ}$ longitude. Wind and temperature fields from ECMWF are used to force the advection. Potential vorticity (PV) is also a prognostic variable of the model; it is advected like any other tracer and relaxed towards ECMWF values with a relaxation time constant of 10 days. Previous work shows that the model-calculated PV field is more reliable than that of ECMWF for tracer studies and that the model is able to describe horizontal scales in the stratosphere with an accuracy of better than $100 \mathrm{~km}$ (Fierli et al., 2002).

During the analysis phase, the KF equations are solved in observation space using the Physical-space Statistical Analysis System (PSAS) approach (Cohn, 1998). The observation error covariance matrix is designed to be diagonal (i.e. the observations are uncorrelated). In the background error covariance matrix, the time evolution of the diagonal elements (variances) is computed explicitly following the approach of Ménard and Chang (2000); The off-diagonal elements are the product of the square root of these variances and a correlation function that is flow-dependent and speci- fied in terms of distance and PV (El Amraouli et al., 2004). $\mathrm{PV}$ is a quasi-conserved tracer on short time scales (i.e. a few days) in the stratosphere and is therefore an indicator of the structure of the flow. The representativeness error is designed to be proportional to the observation error, with a constant proportionality factor applied over the entire model domain, reflecting the error associated with interpolating to the observation location and resolution differences between the observations and model. The proportionality factor and correlation lengths (as discussed above) are tuned by minimising the Root-Mean-Square of the innovation vector (i.e. Observation-minus-Forecast).

\section{Humidity observations}

This section describes the observational data used in this study, including the MIPAS data assimilated, the independent observations used for validation and the climatology used to better visualise the biases. A description of both the instrument and its accuracy is given.

\subsection{MIPAS}

MIPAS (Fischer and Oelhaf, 1996) is a Michelson Interferometer launched aboard ENVISAT in March 2002. By passively sounding the atmosphere in the near infrared, vertical profiles of trace gases such as water vapour can be determined. MIPAS humidity profiles are available from 12 $60 \mathrm{~km}$. The estimated error standard deviation for $\mathrm{v} 4.61$ is $10-20 \%$ near the tropopause, $3-10 \%$ in the $15-40 \mathrm{~km}$ layer, and $3-15 \%$ in the $40-60 \mathrm{~km}$ layer; the total error (random plus systematic, i.e. bias) is $20-25 \%$ near the tropopause, $15-20 \%$ in the $15-40 \mathrm{~km}$ layer, and $20-50 \%$ in the $40 \mathrm{~km}-$ $60 \mathrm{~km}$ layer (Raspollini et al., 2006). The main systematic errors are associated with spectroscopy and horizontal temperature errors. Comparison of the MIPAS humidity profiles with balloon and aircraft data (Oelhaf et al., 2004); groundbased radiometer and lidar data (Pappalardo et al., 2004); and HALOE, SAGE II and POAM III satellite data (Weber et al., 2004), shows good agreement between $15 \mathrm{~km}$ and $30 \mathrm{~km}$. However, above $30 \mathrm{~km}$ the MIPAS retrievals have a positive bias of up to $20 \%$ compared to the satellite data and of $7-15 \%$ compared to ground-based radiometer and lidar data. Juckes (2007), when comparing MIPAS data to other satellite data, found that in general MIPAS data compared most favourably with HALOE data, with larger departures from the SAGE II and POAM III data sets. In the lower stratosphere MIPAS is marginally wetter (by 5\%) than HALOE and SAGE II data, while MIPAS data is significantly drier than POAM III data (by more than 15\%). In the upper stratosphere POAM III data compares most favourably with MIPAS data, while MIPAS data is wetter than HALOE (10\%) and drier than SAGE II $(>10 \%$ at $1 \mathrm{hPa})$. Lahoz et al. (2006) also document the relatively poor quality of v4.61 MIPAS water vapour in the 

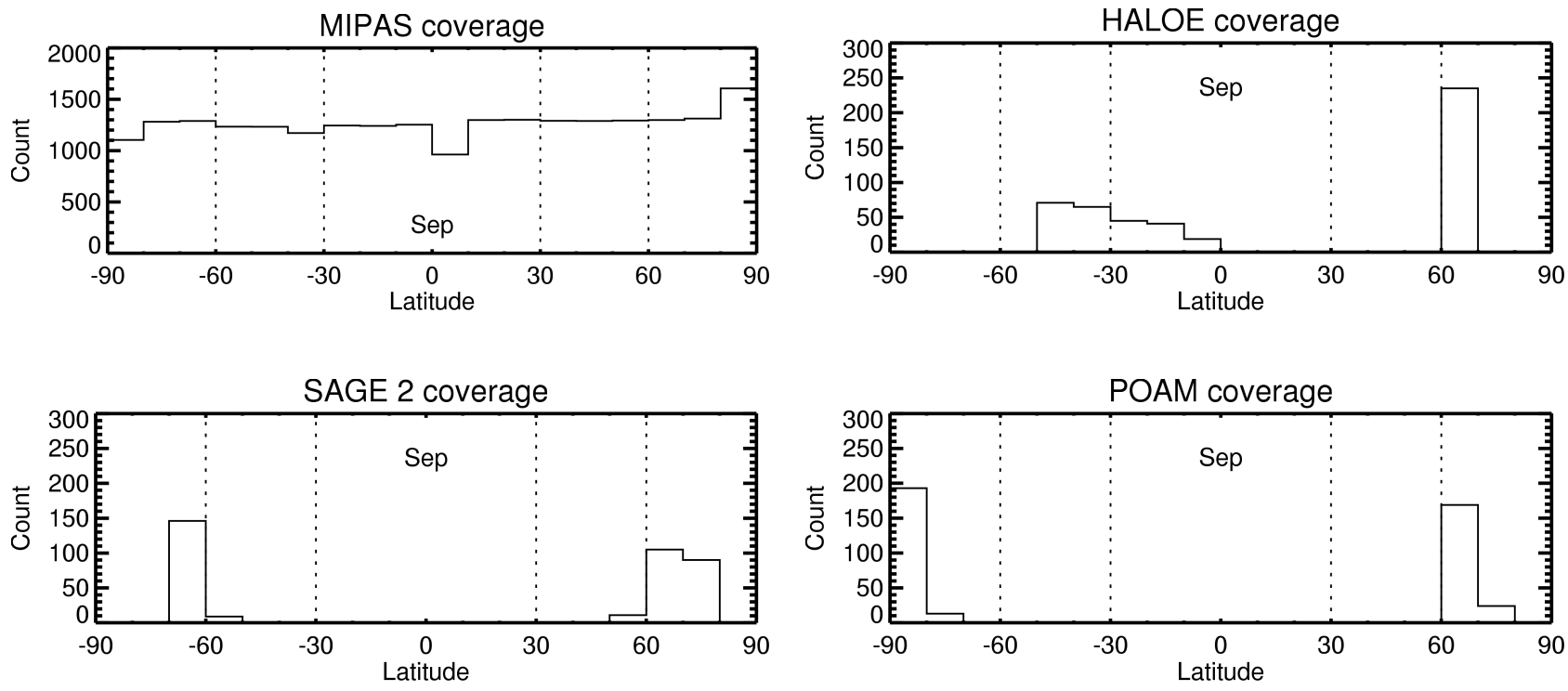

Fig. 1. Latitudinal coverage of MIPAS (top left), HALOE (top right), SAGE II (bottom left) and POAM III (bottom right) profiles over the intercomparison period (29 August-29 September 2003). Data are collected in $10^{\circ}$ latitude bins.

southern winter upper stratosphere, where unrealistically wet values were found. In the UTLS region the MIPAS retrievals have a small negative bias compared to the balloon and aircraft data. The good spatial coverage of the MIPAS data is highlighted in Fig. 1, which shows that there are at least 900 profiles available in each $10^{\circ}$ latitude bin during September 2003.

\subsection{HALOE}

The Halogen Occultation Experiment (HALOE; Russell III et al., 1993) uses solar occultation to derive atmospheric constituent profiles. We use Version 19 HALOE data, which is available from the HALOE website (http://disc.sci.gsfc. nasa.gov/data/datapool/UARS/HALOE/). For water vapour there is a combined systematic and random uncertainty in the lower stratosphere of between $14 \%$ and $24 \%$, and up to $30 \%$ in the upper stratosphere. The agreement with correlative measurements is typically better than $10 \%$ (Harries et al., 1996; Kley et al., 2000). The agreement with SAGE II water vapour measurements (version 6.2) is better than $10 \%$ in the $15-40 \mathrm{~km}$ region (Taha et al., 2004), with the HALOE water vapour exceeding SAGE II everywhere except in the $15-20 \mathrm{~km}$ range. The solar occultation technique means that the vertical resolution of the retrievals is high, $\sim 2 \mathrm{~km}$, but it also means that the data are sparse in time and space, with about 15 observations (for both sunrise and sunset) per day at each of two latitudes. During September 2003 HALOE data are only available between around $0^{\circ} \mathrm{N}$ to $50^{\circ} \mathrm{S}$ and 60 $70^{\circ} \mathrm{N}$ (Fig. 1). Table 1 summarises the relative biases found between the different satellite instruments.

\subsection{SAGE II}

The Stratospheric Aerosol and Gas Experiment II (SAGE II) sensor was launched in 1984 and also uses solar occultation to derive atmospheric constituent profiles (Mauldin III et al., 1985). The vertical resolution of the measurements is $\sim 500 \mathrm{~m}$. We use version 6.2 data (Thomason et al., 2004), which are available from http://www-sage2.larc.nasa. gov/index.html. In the $15-40 \mathrm{~km}$ altitude range, the combined random error for single profiles is between $10 \%$ and $20 \%$. In addition, the measurement bias seen in previous retrieval versions has been almost totally eliminated in version 6.2 (Thomason et al., 2004). Up to $40 \mathrm{~km}$, the SAGE II data agree within $10 \%$ with frost point hygrometer, HALOE, POAM III and ILAS (Improved Limb Atmospheric Spectrometer) data, and within 15-20\% with Mk IV interferometer data (Taha et al., 2004). In this range, the SAGE II values are less than those from POAM III at all levels and less than those from HALOE everywhere apart from below $20 \mathrm{~km}$. Above $40 \mathrm{~km}$, SAGE II water vapour profiles are often noisy and show an increasing positive bias (up to 20\% compared to HALOE data). Around the hygropause, comparison with other satellite-borne instruments is often problematic, but comparison with balloon-borne instruments (frost point hygrometer and the Mk IV interferometer) shows agreement to within $10 \%$ (Taha et al., 2004). Observational coverage for September 2003 is shown in Fig. 1.

\subsection{POAM III}

The Polar Ozone and Aerosol Measurement III (POAM III) sensor is a solar occultation instrument which flies on a 
Table 1. A summary of water vapour biases between MIPAS, HALOE, POAM III and SAGE II instruments in the stratosphere and lower mesosphere.

\begin{tabular}{llll}
\hline & HALOE & POAM III & SAGE II \\
\hline MIPAS & Lower strat: & Lower strat: & Lower strat: \\
& MIPAS 5\% wetter & MIPAS $>15 \%$ drier & MIPAS 5\% wetter \\
& Upper strat and meso: & Upper strat and meso: & Upper strat and meso: \\
& MIPAS 10-20\% wetter & Good comparison & MIPAS $>10 \%$ drier \\
HALOE & & Lower strat: & Lower strat: \\
& & POAM III 5-10\% wetter & HALOE is $<10 \%$ wetter \\
& & & (except 15-20 km) \\
& & Upper strat: & Upper strat and meso: \\
& & POAM III is wetter & SAGE II $<20 \%$ wetter \\
& & & Lower strat: \\
POAM III & & & SAGE II 10\% drier \\
\hline
\end{tabular}

spacecraft with a polar, sun-synchronous orbit; it provides 14 solar occultation measurements per day around two circles of latitude, one for each hemisphere. Northern hemisphere measurements are made at local sunset, and Southern hemisphere measurements are made at local sunset from October to March and at local sunrise from April to September (our period of interest). Because of the satellite orbit used, all the observations are at high latitudes. We use Version 4 data, which are available from http://wvms.nrl.navy. $\mathrm{mil} / \mathrm{POAM} /$ poam.html. The vertical resolution of the humidity retrievals is $1 \mathrm{~km}$ in the lower stratosphere, rising to $3 \mathrm{~km}$ in the upper stratosphere. Lumpe et al. (2006) show that Version 4 retrievals have a precision of $5-7 \%$ throughout the stratosphere. They are biased high compared to correlative observations in the lower and middle stratosphere. Comparisons with HALOE and SAGE II data also indicate differences between sunrise and sunset POAM III retrievals, with sunset retrievals larger than sunset retrievals by $5-10 \%$. In the northern hemisphere, POAM III water vapour is around 5-10\% high compared to all correlative observations in the $12-35 \mathrm{~km}$ range. At higher levels, around $40 \mathrm{~km}$, POAM III values exceed HALOE values but are fairly similar to MIPAS values. Figure 1 also highlights the poor availability of observational data for studying the humidity of the stratosphere prior to the launch of ENVISAT.

\subsection{UARS climatology}

To better understand how the different analyses compare with the independent data, the comparison is normalised by the UARS humidity field. This process is explained in Sect. 4. UARS water vapour profiles were taken from the UARS Reference Atmosphere Project website (http://code916.gsfc. nasa.gov/Public/Analysis/UARS/urap/home.html). The data selected are the extended HALOE/MLS dataset, which gives humidity profiles up to $0.1 \mathrm{hPa}$, in the form of zonal monthly mean fields. A water vapour climatology field was created on the intercomparison grid (described in Sect. 4), for every 6-h period over the intercomparison. This was done by linearly interpolating the monthly mean files in time, by assuming the UARS monthly mean files represent the 15th of every month. The UARS monthly mean fields are only available up to 80 degrees north/south in the stratosphere and to 65 degrees north/south in the mesosphere. MIPAS and the independent data are available at higher latitudes and consequently the climatology was extended horizontally at constant value. Although this assumption may modify the relative biases, it was felt justified to enable the higher latitudes to be analysed.

\section{Method}

As in the ozone intercomparison described by Geer et al. (2006), the humidity analyses have been interpolated onto the same common grid, prior to interpolation to observation locations for comparison. The common grid is $3.75^{\circ}$ longitude by $2.5^{\circ}$ latitude, with 19 pressure levels. The pressure levels are those used in the UARS project, with 6 pressure levels per decade between $0.1-100 \mathrm{hPa}$. In the vertical, interpolations were done linearly in the natural logarithm of the pressure. Horizontally, the interpolation is bi-linear in both longitude and latitude. Analyses are available every 6-h for comparison with observations. There is therefore a maximum of a 3-h time difference between compared observation profiles and analyses.

The observations are interpolated onto the common grid vertical levels to ease comparison, as the different observations have different vertical resolutions. The observations that are used in the intercomparison have been quality controlled. For each profile, at each level, the observation must not be greater than the UARS climatology by more than 
$120 \%$, otherwise it is flagged as missing. This has the impact of removing the observation profiles which are significantly different from the climatology, effectively removing outliers. None of the HALOE profiles were removed by this process, however $2 \%, 8 \%$ and $12 \%$ of MIPAS, SAGE II and POAM III profiles were removed respectively. The UARS climatology was made up of HALOE and MLS observations and therefore explains the good agreement between the HALOE data and the climatology. The removal of the other outlying observational profiles avoids poor data skewing the biases. For example, prior to the data consistency check, the extra SAGE II data produced very large biases in the southern hemisphere mid latitude lower stratosphere. The loss of data due to the quality control procedure is sufficiently small to avoid any significant loss of data coverage. Sensitivity tests completed by Geer et al. (2006) for the ozone comparison (this uses a 12 hourly temporal resolution) show the chosen temporal and spatial resolution of the common grid has little impact on the mean differences between ozone observations and analyses for levels below $0.5 \mathrm{hPa}$. Above $0.5 \mathrm{hPa}$, the processes that govern the ozone distribution have a timescale shorter than $12 \mathrm{~h}$. For example, in regions of rapid transport such as the polar vortex, or within the slow ascent of the tropics, the grid resolution had little impact on the mean differences. In the mid-latitude UTLS, the temporal resolution was found to be more important and therefore the comparison was completed every $6 \mathrm{~h}$. Like ozone in the lower and middle stratosphere, water vapour can be considered a tracer species in the stratosphere and lower mesosphere, because the oxidation of methane or the photolysis of water vapour represents small terms in the water vapour budget compared to the transport term. Furthermore, the processes that govern the water vapour distribution have a time-scale longer than the temporal resolution of the common grid. Therefore, the grid chosen for the water vapour analysis is not expected to strongly influence the differences found between the water vapour observations and the analyses. Figure 2 illustrates that the common grid is capable of capturing most of the vertical variability in specific humidity in the upper stratosphere and lower mesosphere seen in the HALOE profile.

Figure 2 also highlights where particular analyses have problems assimilating the MIPAS profiles. The large dry bias in the mesosphere and the wet bias in the upper stratosphere of the Met Office analyses can clearly be seen. Due to the poor performance of the Met Office humidity assimilation scheme, its results are not presented along side the other analyses but rather discussed in Sect. 6. The increasing ECMWF wet bias with altitude in the lower mesosphere is due to an incorrect use of the MIPAS observations above the model top, inflicting a wet bias in the specific humidity field down to about $0.5 \mathrm{hPa}$. Some MIPAS partial columns were partially above the top of the ECMWF model, and for the part above the model top, the model humidity was erroneously taken to be zero. Such data should have been excluded in the ECMWF analyses. In the following, we will

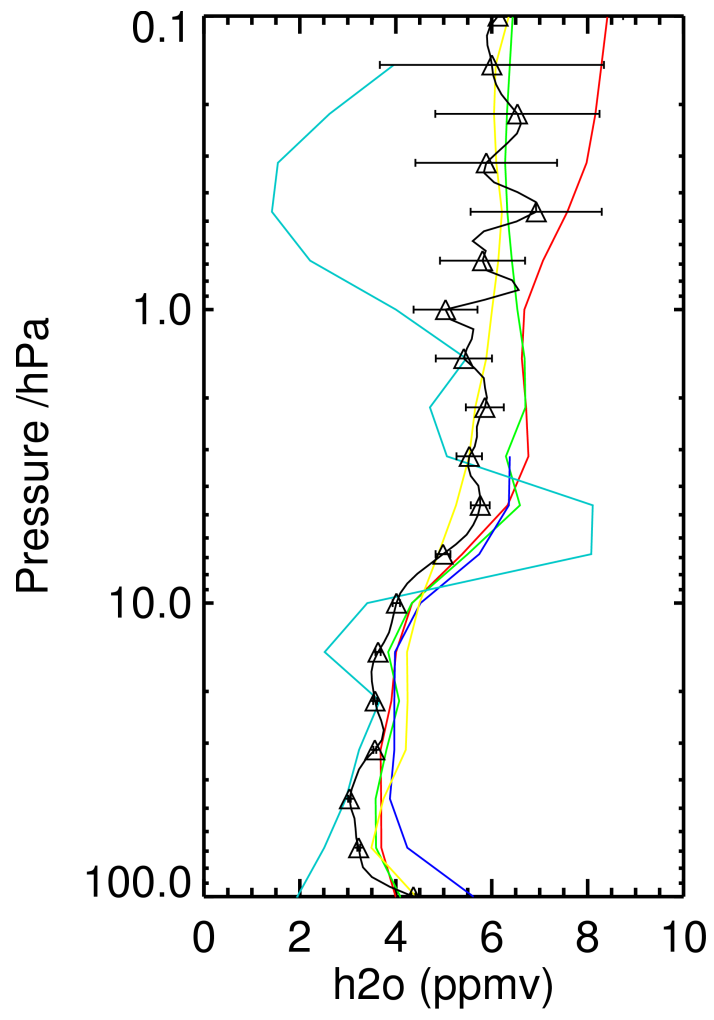

Fig. 2. Comparison of a HALOE profile at a resolution of 30 points per decade (black line), HALOE values (black triangles) and error bars on common grid levels with the four analyses, ECMWF (Red), BASCOE (Green), MIMOSA (Dark Blue) and the Met Office (Light Blue), and the UARS climatology (Yellow) on 2 September 2003 at $04: 19,6.45^{\circ} \mathrm{E}, 65.73^{\circ} \mathrm{N}$.

therefore discard the ECMWF analyses above $0.5 \mathrm{hPa}$. This limit was chosen on the basis of departure statistics for MIPAS retrievals and background error correlations.

Like the analysis fields, the UARS climatology is firstly interpolated onto the common grid and secondly to observation locations, to enable the relative difference in the biases with height to be seen. At each observation profile location and common grid level, the difference in specific humidity between the observation and the different analyses is calculated and then normalised by the corresponding UARS climatological value, as in Geer et al. (2006, Sect. 4). The average normalised difference per level and per latitude bin is then calculated. Percentage differences are calculated for five latitude bands for ease of comparison; the high latitudes (90$\left.60^{\circ}\right)$ and the mid latitudes $\left(60-30^{\circ}\right)$ in both hemispheres, and the tropics $\left(30^{\circ} \mathrm{S}-30^{\circ} \mathrm{N}\right)$. The intercomparison period runs from 29 August 2003 to 29 September 2003. All the experiments commenced at least 10 days prior to the start of the intercomparison period (18 August, 15 August, July 2002 and 4 August for the ECMWF, MIMOSA, BASCOE and Met Office analyses, respectively). The intercomparison period was chosen such that any spin up issues were resolved prior to the start of the intercomparison period. 
Table 2. The percentage of MIPAS observations rejected by each observational quality control system. No quality control has been applied in the MIMOSA system, consequently all MIPAS retrievals have been assimilated. Higher rejection rates occur for the Tropics and the South Polar region for at least one system, so these regions are shown separately. For other regions rejection rates are low, typically well below $10 \%$.

\begin{tabular}{rrrrr}
\hline & $\begin{array}{r}\text { Pressure } \\
\text { range }\end{array}$ & $\begin{array}{r}\text { All latitudes } \\
\text { latitudes }\end{array}$ & $\begin{array}{r}\text { Tropics } \\
(-30: 30)\end{array}$ & $\begin{array}{r}\text { South Polar } \\
\text { region }(-60:-90)\end{array}$ \\
\hline ECMWF & $100 \mathrm{hPa}-20 \mathrm{hPa}$ & $11 \%$ & $14 \%$ & $38 \%$ \\
& $20 \mathrm{hPa}-0.7 \mathrm{hPa}$ & $1 \%$ & $0 \%$ & $2 \%$ \\
BASCOE & $100 \mathrm{hPa}-20 \mathrm{hPa}$ & $5 \%$ & $1 \%$ & $29 \%$ \\
& $20 \mathrm{hPa}-0.1 \mathrm{hPa}$ & $17 \%$ & $7 \%$ & $28 \%$ \\
\hline
\end{tabular}

\section{Results}

\subsection{September monthly mean 12:00 UT analysis}

Figure 3 shows the monthly mean zonal water vapour analyses for the intercomparison period for the ECMWF, BASCOE and MIMOSA systems. The UARS climatology water vapour field is also included. A number of well-known features can be seen in the stratospheric analyses and climatology. These include the very dry tropical tropopause region (near $100 \mathrm{hPa}$ ) and the dehydration within the Antarctic winter polar vortex (between 100-50 hPa Kley et al., 2000). The presence of a layer of dry $(\sim 3 \mathrm{ppmv}$ - parts per million by volume) air around the 100-200 hPa suggests that some of the air coming into the stratosphere in the tropics may be being transported rapidly polewards. This is in agreement with previous observational studies (e.g. Jackson et al, 1998). There is also an indication of slow upward transport of dry air at low latitudes via the Brewer-Dobson circulation. As the air is transported upwards, methane oxidation leads to an increase in humidity, which is reflected in the relatively moist air seen in the upper stratosphere and lower mesosphere (levels above $10 \mathrm{hPa}$ ). Near the stratopause (near 1 $\mathrm{hPa}$ ) the water vapour patterns are consistent with overturning of the stratospheric air related to a change in the pattern of the Brewer-Dobson circulation. This change implies the replacement of upward low latitude transport by poleward transport and associated downward transport at high latitudes of moist air from the upper stratosphere / lower mesosphere to lower levels. This pattern is most apparent in the winter high latitudes, where downward transport is stronger.

The regions of the middle atmosphere where the specific humidity analyses differ from one another can be divided into the tropical water vapour minimum, the UTLS, the southern hemisphere polar vortex and the upper stratosphere and lower mesosphere (USLM). In the tropical UTLS, the shape and depth of the water vapour minimum differs from one analysis to another. The strength and extent of the southern hemisphere polar vortex also varies between the analyses, with MIMOSA appearing to have the smallest extent, while BASCOE has the largest and driest vortex. Between $1 \mathrm{hPa}$ and $10 \mathrm{hPa}$, the moist centres associated with the descending arm of the Brewer-Dobson circulation vary in magnitude between the analyses, where BASCOE appears marginally drier. Above $1 \mathrm{hPa}$, the ECMWF analysis is considerably wetter at all latitudes than BASCOE.

When comparing the analyses to the UARS climatology, the features of the specific humidity fields are similar, although the climatology is generally less extreme, with a wetter UTLS and a drier USLM. As explained in Sect. 3 the MIPAS data assimilated in the analyses have a dry bias in the UTLS and wet bias in the USLM compared to most observation types and this therefore may explain these differences.

\subsection{Comparison with MIPAS and independent data}

In this section, the ECMWF, BASCOE and MIMOSA analyses are compared with MIPAS data and with independent data from HALOE, SAGE II and POAM III. The comparison with MIPAS data is a consistency check of the assimilation algorithms as this data has been assimilated to produce the analyses. The comparison with the other non-assimilated data is an independent evaluation of the quality of the resultant analyses. The discussion is focused on the mean differences between the analyses and these data, and the standard deviation of this difference in the five different latitudinal bands. Each section of the middle atmosphere is taken in turn, starting with the UTLS, followed by the upper stratosphere, finishing with the lower mesosphere. Rejection statistics for the MIPAS retrievals for the different assimilation systems are summarised in Table 2. For the ECMWF and the BASCOE system, observations are rejected from the assimilation if they deviate too much from the model background field, in order to remove outliers. No such quality control is included by MIMOSA. Higher rejection rates occur over the South Polar region and the Tropics for at least one assimilation system, and these regions are shown separately in Table 2. Elsewhere, rejections are typically less than $10 \%$, suggesting few outliers in the MIPAS retrievals. Higher rejections can reflect problems with the model background or the observations, or may result from stricter quality control. 

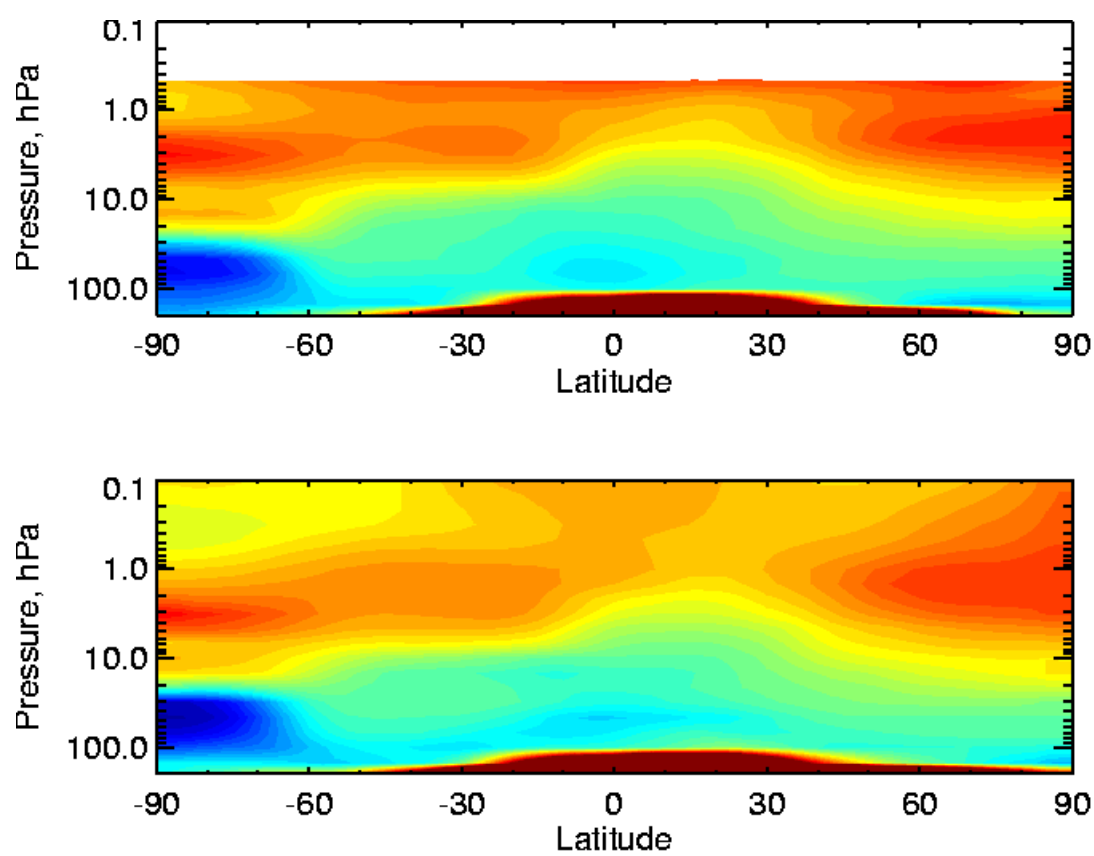

6
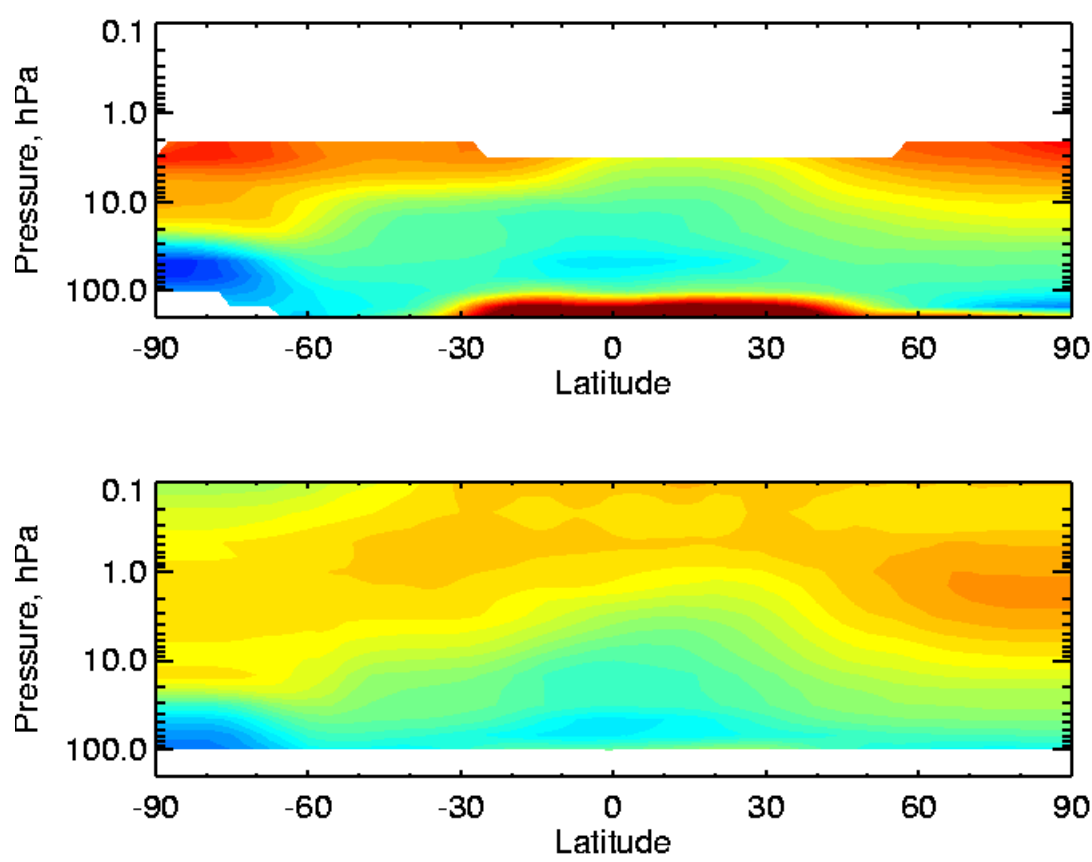

Fig. 3. Monthly zonal mean specific humidity (ppmv) analyses for the intercomparison period for ECMWF (top), BASCOE (upper middle) and MIMOSA (lower middle) and UARS climatology (bottom). MIPAS water vapour profiles have been assimilated in all cases except the UARS Climatology.

\subsubsection{Upper troposphere lower stratosphere}

The distinctive water vapour features of the UTLS region can be seen in Fig. 3, including the tropical $(\sim 50-70 \mathrm{hPa}$, $30^{\circ} \mathrm{S}-30^{\circ} \mathrm{N}$ ) and the southern hemisphere high latitude water vapour minima. As described by Kley et al. (2000), the tropical water vapour minimum is generated around February, when the coldest tropopause temperatures have dehy- drated the rising air. The vertical transport of the BrewerDobson circulation in the lower latitudes, has lifted this dry air to the position seen in Fig. 3. This feature is described in detail in Mote et al. (1996) and it is referred to as the "tropical tape-recorder". The southern hemisphere water vapour minimum is associated with the cold interior of the polar vortex. 


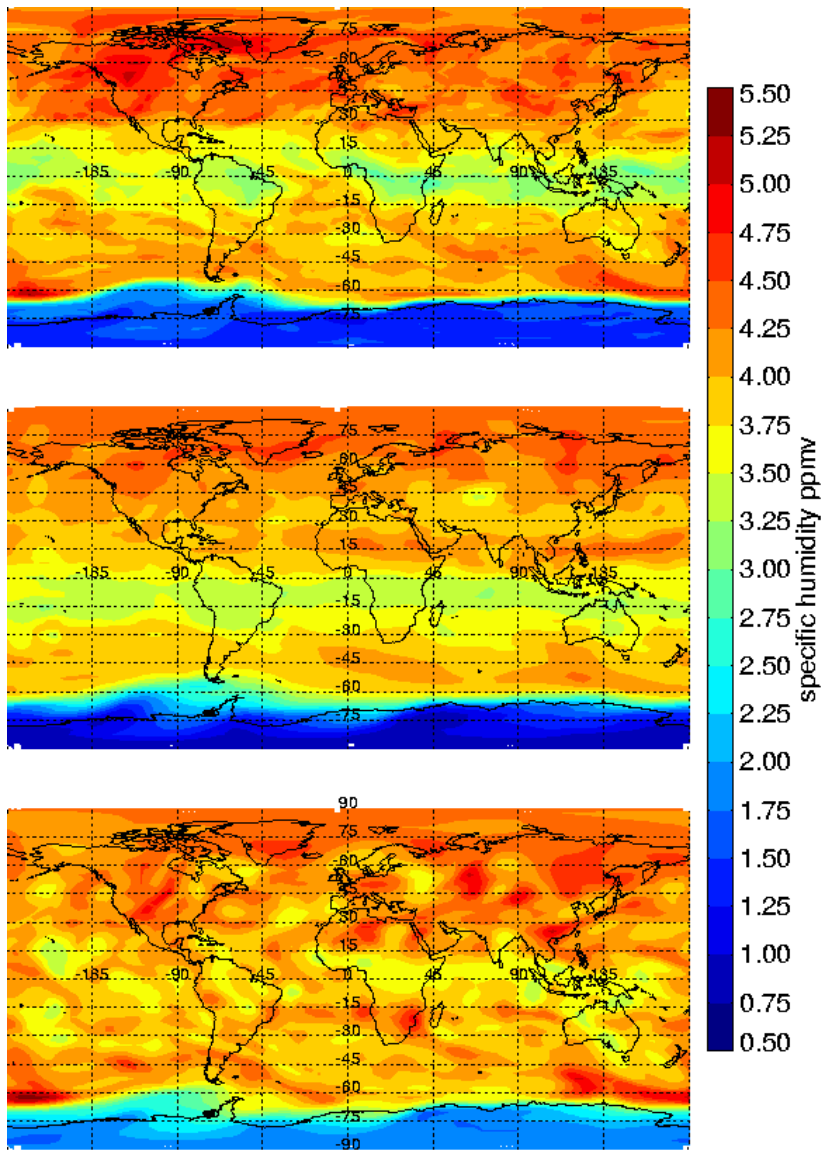

Fig. 4. Specific humidity field (ppmv) at $68 \mathrm{hPa}$ on the 21 September 2003 12:00 UT, for ECMWF (top), BASCOE (middle) and MIMOSA (bottom).

\section{The tropical water vapour minimum}

The coverage and depth of the tropical water vapour minimum in Fig. 3 can be seen to vary between the different analyses. Figure 4 shows how the specific humidity field varies as a function of latitude and longitude at 12:00 UT on 21 September 2003 around the water vapour minimum $(68 \mathrm{hPa})$ in the three analyses. MIMOSA can be seen to have the wettest tropical water vapour minimum and ECMWF the driest. MIMOSA has assimilated the MIPAS observations most successfully in the tropics, as the bias with respect to the observations is almost zero at $68 \mathrm{hPa}$ (Fig. 5). This is as expected, because the assimilation parameters are tuned to minimise the root mean square of the observation minus forecast vector. ECMWF and BASCOE have a small dry bias in comparison with the MIPAS observations of up to $5 \%$ in this region. The standard deviations of the analysis departures are approximately $15 \%$ for all three analyses (Fig. 6). Near the tropical tropopause $(100 \mathrm{hPa})$ the dry biases of ECMWF and BASCOE increase to $20 \%$ and can be seen to occur at most latitudes in the UTLS. The standard deviations increase to $30 \%$ at $100 \mathrm{hPa}$ in the tropics and range between $10 \%$ and $40 \%$ across the different latitudes. The tropospheric set-up of the water vapour in the BASCOE analyses (see Sect. 2.2) explains the close agreement between BASCOE and ECMWF systems in the UTLS. However, the quality control system in ECMWF rejects a much higher percentage of MIPAS observations in the tropical lower stratosphere (14\%) compared to BASCOE (1\%), suggesting the ECMWF scheme may be more strict in this region.

HALOE data are the only independent data set in the tropical UTLS available to assess the realism of the different water vapour minima in the analyses. Figure 5 shows that between $50 \mathrm{hPa}$ and $70 \mathrm{hPa}$ BASCOE matches the HALOE observations most closely, with ECMWF and MIMOSA having a wet bias of 10-20\%. However nearer the tropopause the biases are more similar to those with the MIPAS data, with ECMWF and BASCOE having dry biases of 5\% and $10 \%$ respectively. The standard deviations of the differences range between $10 \%$ and $15 \%$ for the different analyses. HALOE has been found by Juckes (2007) to have a 5\% dry bias relative to MIPAS data and therefore this partly explains the differences seen.

\section{Southern hemisphere polar vortex}

Another problematic region in the lower stratosphere for the assimilation of humidity observations is the southern hemisphere polar vortex. In this region the persistent strong zonal flow acts as a barrier to meridional flow. In the very cold polar winter, the air trapped within the vortex is cooled and this allows PSC generation, leading to removal of water vapour and very dry air. Figure 3 highlights the strong humidity gradient between the dry polar air and the wetter air at mid latitudes and higher altitudes.

Figures 5 and 6 highlight the ability of the different systems to assimilate the MIPAS observations in the southern hemisphere lower stratosphere. MIMOSA again assimilates the MIPAS observations effectively with a dry bias and a standard deviation of less than $10 \%$ and $30 \%$, respectively. ECMWF and BASCOE have larger dry biases of $20 \%$ and up to $60 \%$, respectively, and standard deviations ranging between $10 \%$ and $40 \%$. The BASCOE dry bias and standard deviation peak at $30 \mathrm{hPa}$ in the Southern Hemisphere high latitudes reaching $60 \%$ and $35 \%$, respectively. This large bias is likely to relate to the chemistry scheme applied in the BAS$\mathrm{COE}$ system and is discussed later in this section. Figure 7 shows a comparison of MIPAS observations and the analyses, in $10^{\circ}$ latitude bands in the southern hemisphere high latitudes. The dry BASCOE bias reduces from $70 \%$ at $30 \mathrm{hPa}$ between $70-90^{\circ} \mathrm{S}$ to $35 \%$ between $60-70^{\circ} \mathrm{S}$. Both ECMWF and BASCOE rejected a high percentage of MIPAS observations in the lower stratosphere south polar region (38\% and $29 \%$, respectively) and most likely reflects the poor quality of either the MIPAS observations or the model analyses in 

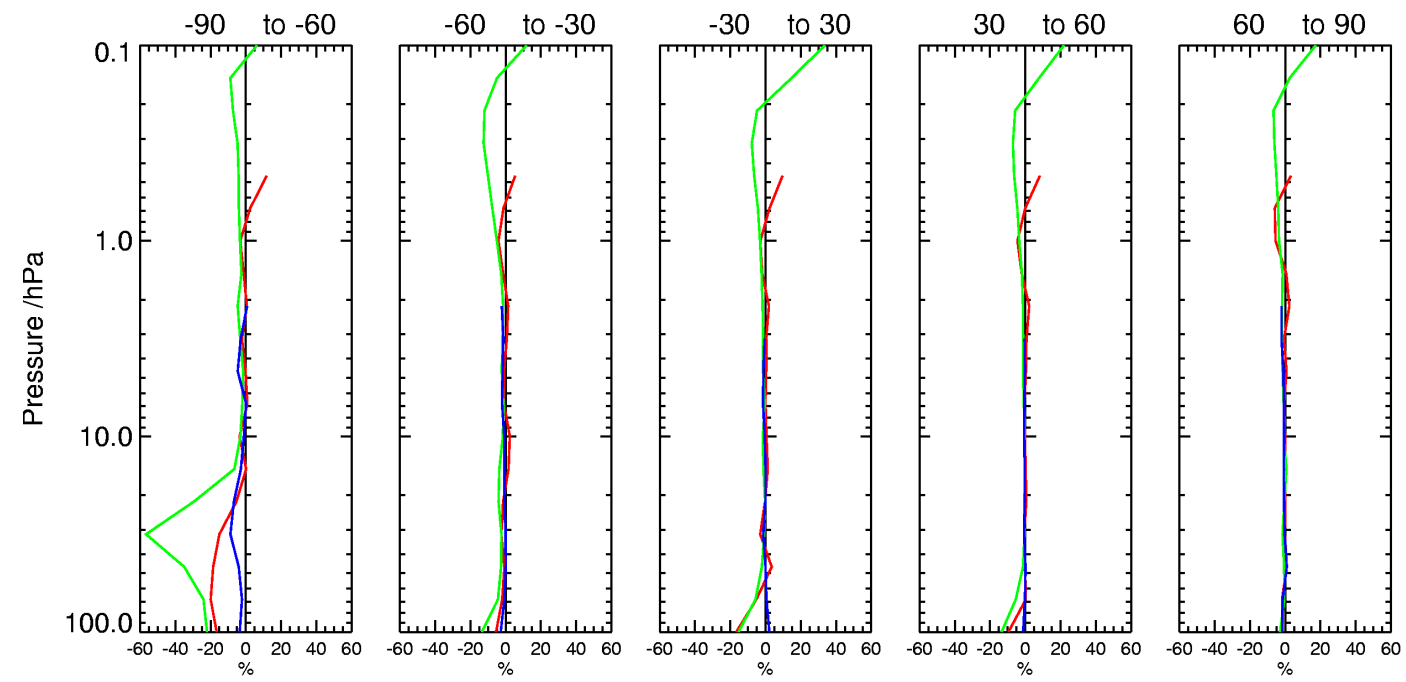

(a) MIPAS
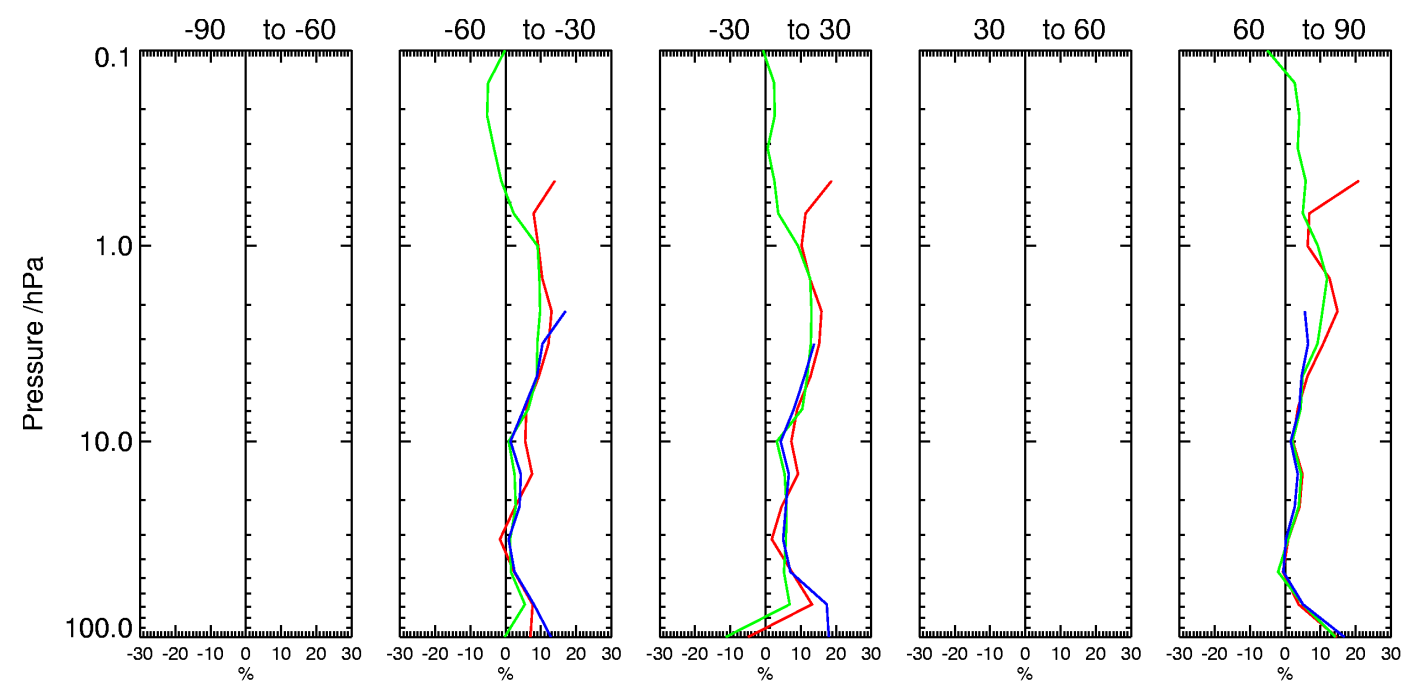

(b) HALOE

Fig. 5. Mean of (Analysis-Observations) water vapour mixing ratio, normalised by climatology (in percent) over the intercomparison period, for ECMWF (Red), BASCOE (Green) and MIMOSA (Blue), for the five different latitude bins. For rows (a) to (d), the analyses are compared with MIPAS, HALOE, SAGE II and POAM III data, respectively. If there are not any satellite profiles available, the graphs are blank.

this region. The large analysis - observation biases in this region suggest the latter maybe important.

With respect to independent data, the water vapour biases in the southern hemisphere high latitudes depend on the instrument considered. Compared to POAM III data, the biases seen for the different analyses are generally similar to MIPAS but slightly larger in magnitude. For example, the dry biases for all three analyses peak at $45 \mathrm{hPa}$ with values of $80 \%, 50 \%$ and $40 \%$ (Fig. 5) for BASCOE, ECMWF and MIMOSA respectively. The analysis departure standard deviations from POAM III observations range between $10 \%$ and $60 \%$ from $10 \mathrm{hPa}$ to $100 \mathrm{hPa}$ for all three analyses. This ties in with the findings of Juckes (2007) that POAM III data is
$15 \%$ wetter than MIPAS in the lower stratosphere. In comparison with SAGE II data, BASCOE again has a dry bias up to $20 \%$ with a standard deviation of $10-20 \%$, both peaking at $30 \mathrm{hPa}$. However, ECMWF and MIMOSA have a wet bias of $5 \%$ and $15 \%$ respectively and both have a standard deviation of $10-20 \%$. The difference in the biases between the analyses and the SAGE II and POAM III data can be explained by: firstly SAGE II data has a dry bias relative to POAM III data (see Sect. 3); secondly, the SAGE II data is sampling the vortex boundary $\left(60-70^{\circ} \mathrm{S}\right)$, whereas POAM III samples the vortex core $\left(>70^{\circ} \mathrm{S}\right)$ and, as shown in Fig. 7, the analysis bias is generally less negative in the former region than in the latter. 

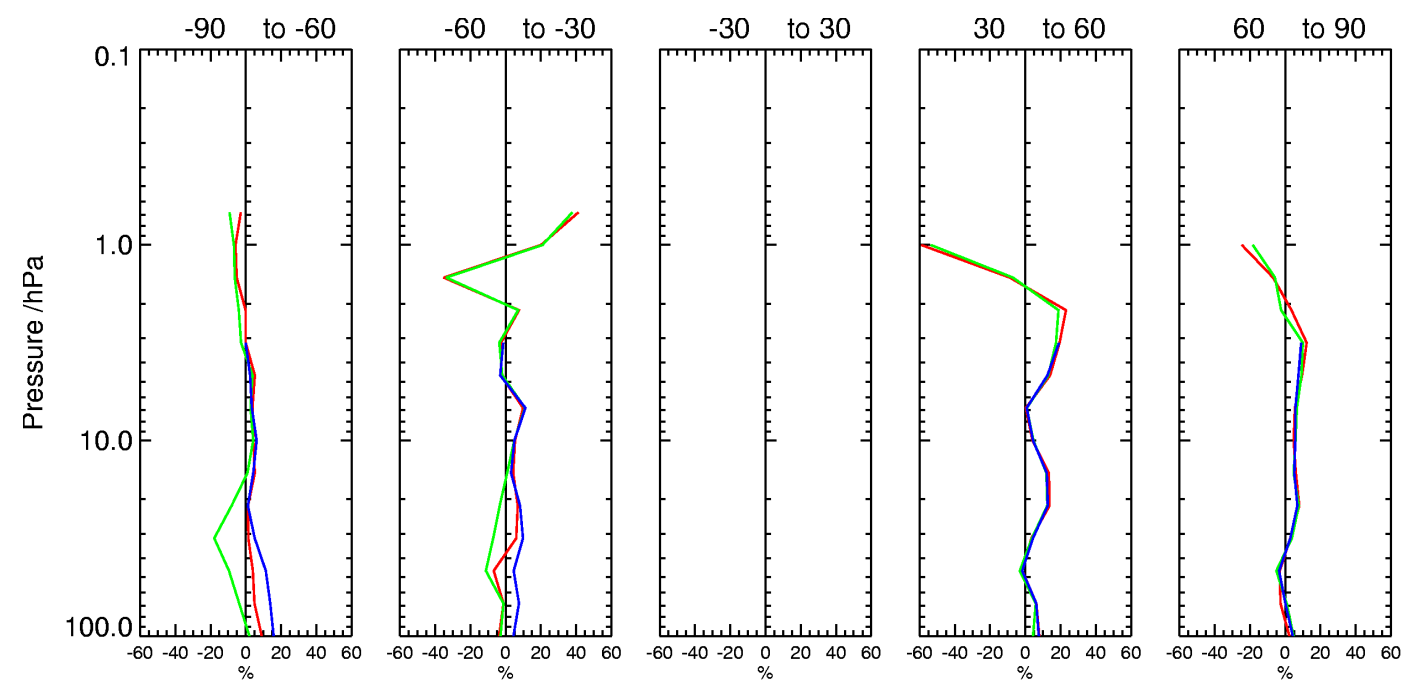

(c) SAGE II
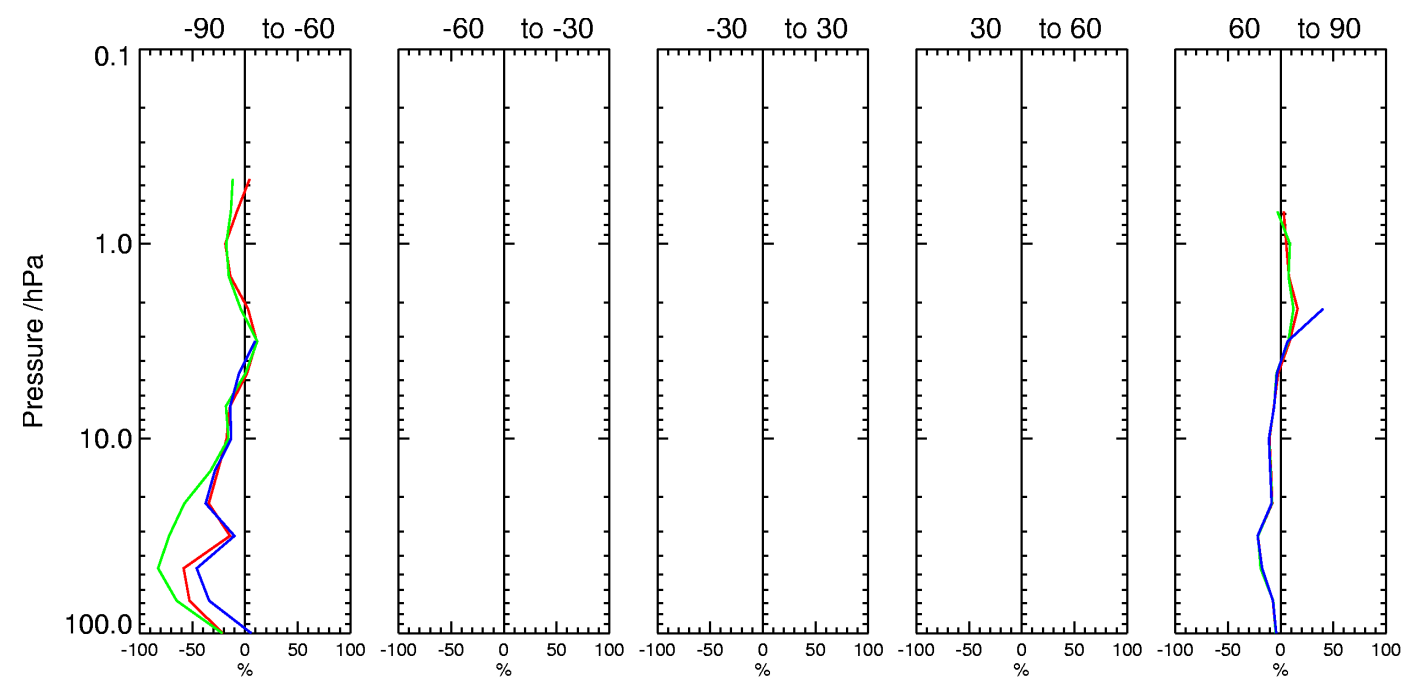

(d) POAM III

Fig. 5. Continued.

To understand the cause of these biases, the analyses will be studied in more depth, concentrating on how the analyses represent the lower stratosphere vortex core moisture minimum $\left(70-90^{\circ} \mathrm{S}\right)$, the latitudinal and vertical extent of this moisture minimum and the transition to wetter mid latitude conditions.

In the analyses, the monthly mean average vortex moisture minimum occurs in the region $70-90^{\circ} \mathrm{S}$ and between 150-30h Pa (Fig. 3). Figure 8 shows the specific humidity field over the southern hemisphere polar region, for each analysis and climatology, for one particular analysis time (12:00 UT, 21 September 2003) at a level within the moisture minimum $(68 \mathrm{hPa})$. The stark contrast between the very dry polar air and the wetter mid latitude air is clearly seen in the zonally symmetric UARS climatology. The dryness of the polar vortex varies between the different analyses, with BASCOE and ECMWF having a drier centre than MIMOSA. Figure 9 shows an individual MIPAS profile on the 21 September 2003, located within the vortex core. In agreement with the latitudinal band averages seen in Fig. 7, MIMOSA compares most favourably with the MIPAS profile between $100 \mathrm{hPa}$ and $50 \mathrm{hPa}$. ECMWF and BASCOE both struggle to assimilate the profile and have dry biases of $20 \%$ and $40 \%$, respectively, although ECMWF lies on the bounds of the observational error bars.

POAM III data are the only available independent data source within the vortex core. Figure 10 shows a comparison between an individual POAM III profile and the different analyses. The uncertainty of the POAM profile within the polar vortex is highlighted by the very large observed error bars. 

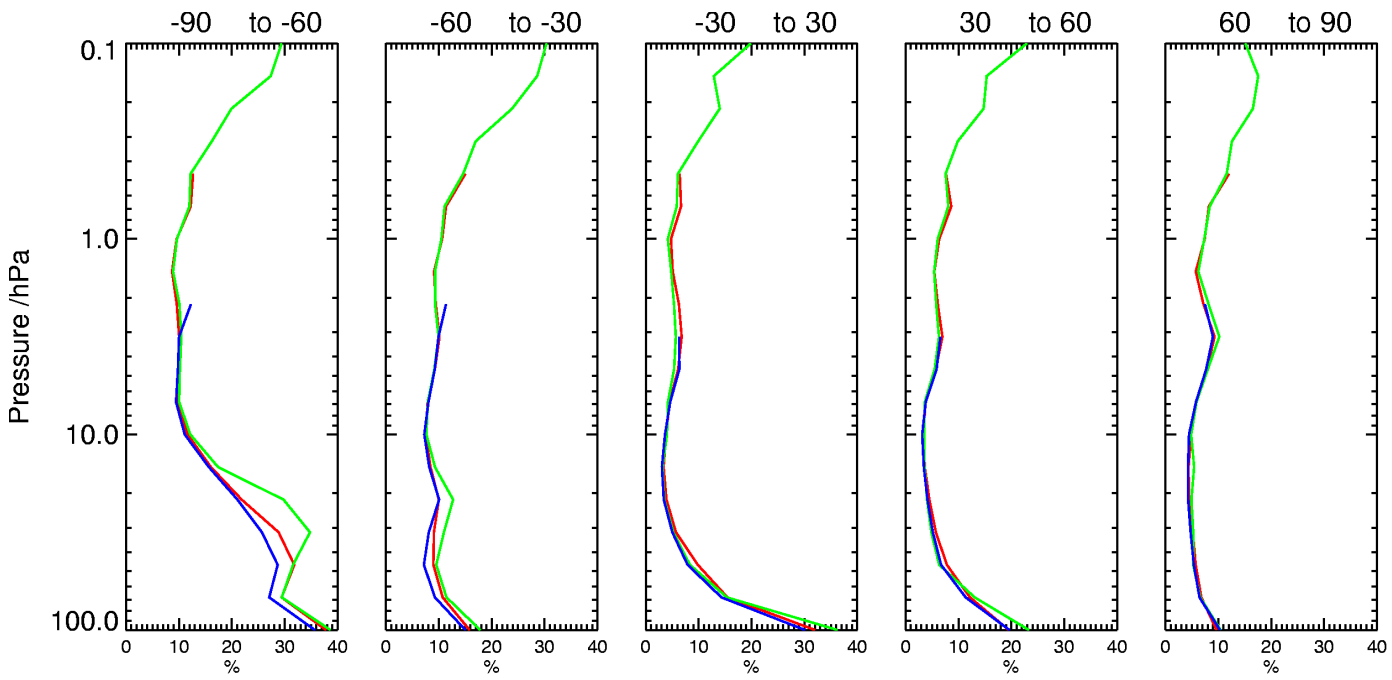

(a) MIPAS
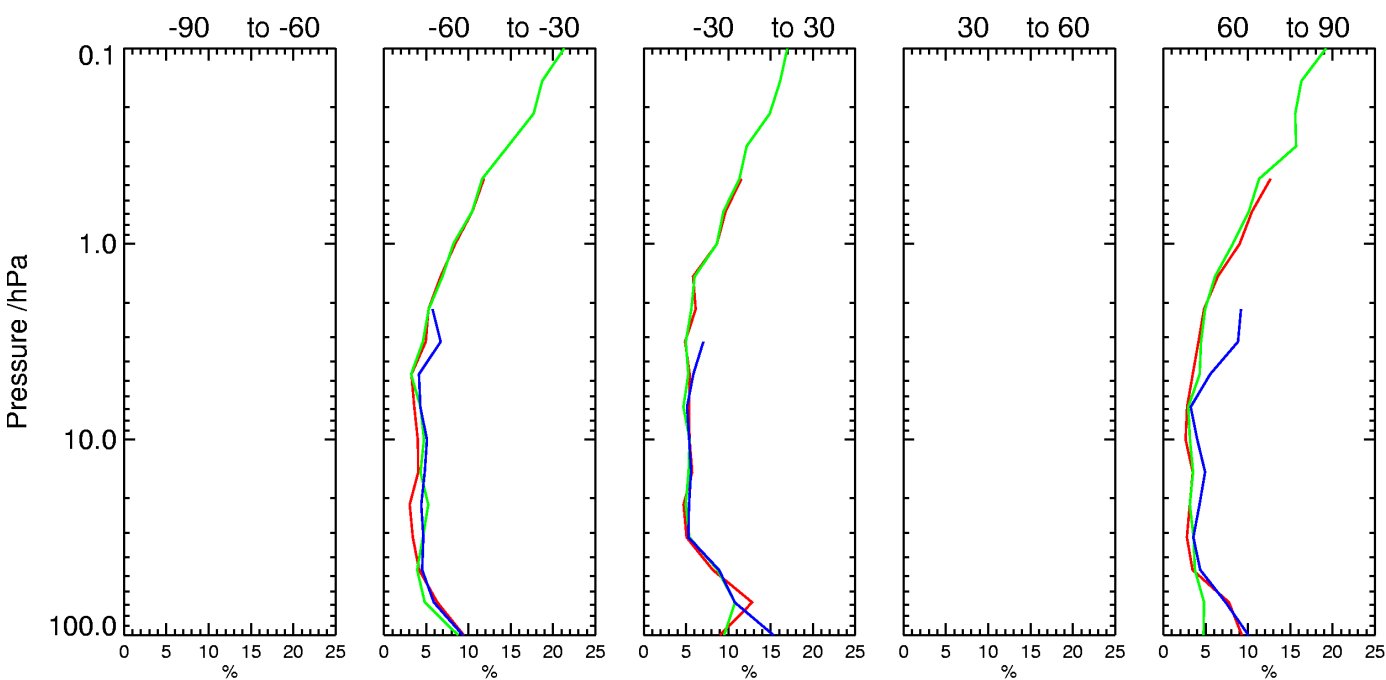

(b) HALOE

Fig. 6. Standard deviation of (Analysis-Observations) water vapour mixing ratio, normalised by climatology (in percent) over the intercomparison period, for ECMWF (Red), BASCOE (Green) and MIMOSA (Blue), for the five different latitude bins. For rows (a) to (d), the observational data is MIPAS, HALOE, SAGE II and POAM III respectively. If there are not any satellite profiles available, the graphs are blank.

In agreement with the single MIPAS profile comparison, MIMOSA is closest to the POAM III profile, while ECMWF and BASCOE have larger dry biases. The dry biases seen are larger than in comparison to the MIPAS profile and again tie in with the POAM III wet bias compared to MIPAS data.

Within the polar vortex, temperature mainly determines the specific humidity, due to the dehydrating impact of PSCs. The PSC sedimentation process is simulated in the BASCOE system, but not in the ECMWF and MIMOSA systems. It is therefore likely that the BASCOE dry bias in the southern hemisphere polar vortex relates to the PSC parametrization, but also the observational quality control scheme. Al- though the BASCOE PSC parametrization scheme can produce a good ozone hole representation Geer et al. (2006), it is likely that the scheme overestimates water vapour loss by PSC sedimentation, producing very dry polar air. To improve the BASCOE analyses in this region, would require an improved PSC sedimentation scheme and a relaxation of the data filtering process.

Both the latitudinal and vertical extent of the southern hemisphere polar water vapour minimum will be studied next. Figure 3 highlights the latitudinal extent of this minimum and how it varies between the different analyses. Although the total size of the region of dry polar air appears 

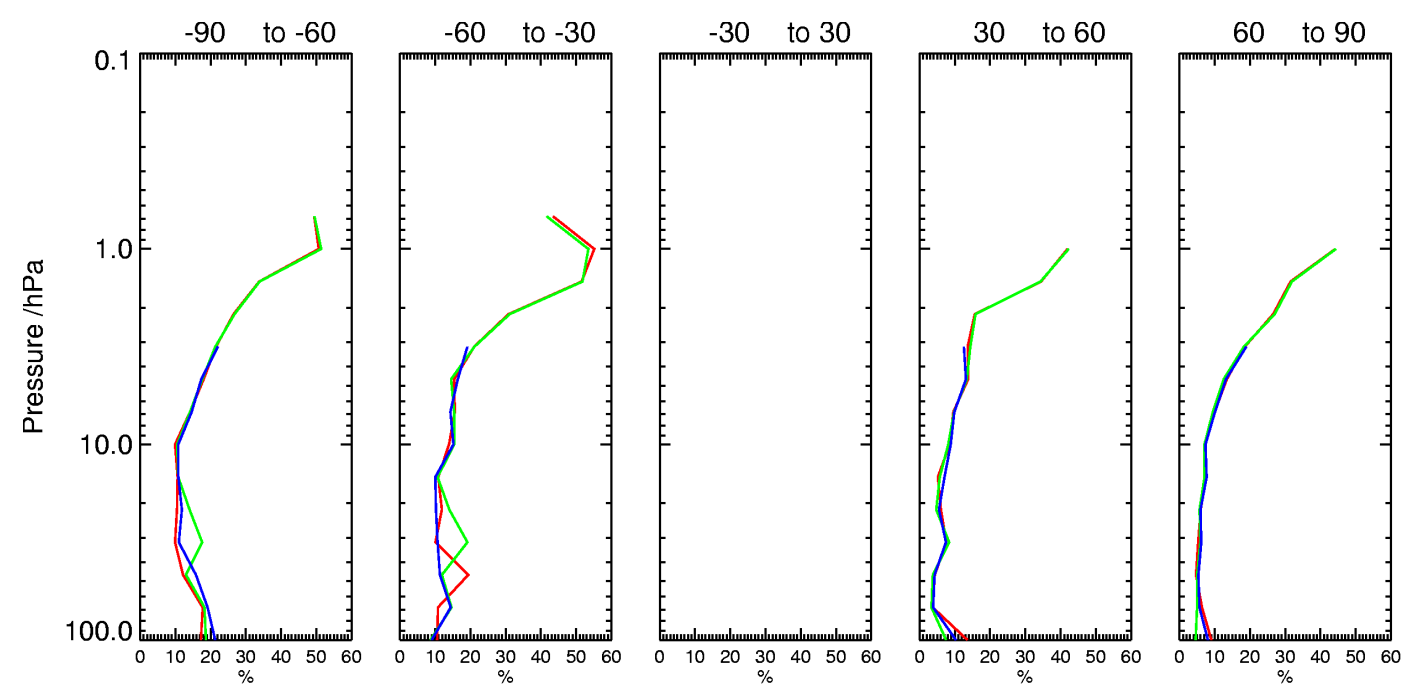

(c) SAGE II
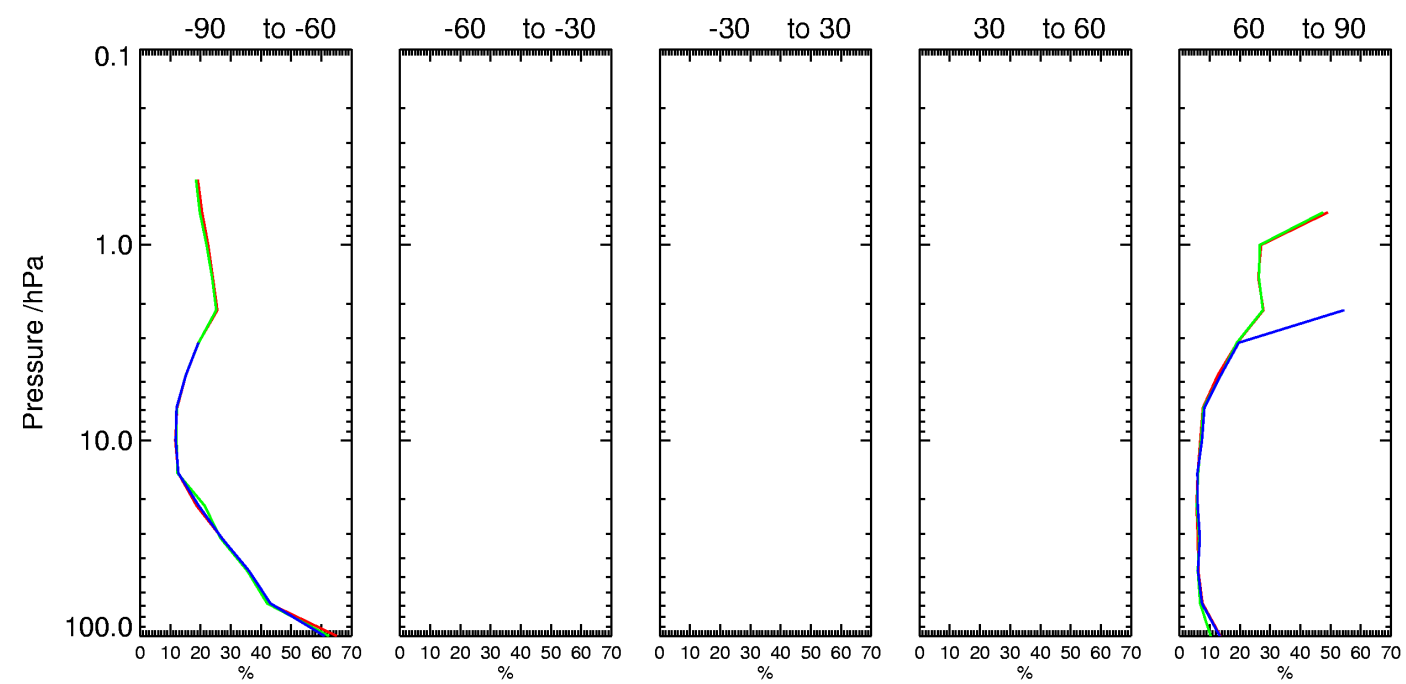

(d) POAM III

Fig. 6. Continued.

approximately constant between the different analyses, the very dry centre in the ECMWF and BASCOE analyses stretches further equatorward than for MIMOSA. For example, the water vapour content at $70^{\circ} \mathrm{S}$ is wetter in MIMOSA monthly mean than in the other two analyses. Figures 4 and 8 also show for one day (12:00 UT, 21 September 2003) that the southern hemisphere polar vortex is smaller in the MIMOSA analysis. By looking at the bias of the analyses with respect to MIPAS data in the $60-70^{\circ}$ band, the faithfulness of the polar vortex extent with respect to MIPAS data between the analyses can be inferred. Figure 7 shows that between $100 \mathrm{hPa}$ and $50 \mathrm{hPa}$ in this latitude band, the MIMOSA bias is negligible, whereas ECMWF and BASCOE have a 20$30 \%$ dry bias. This suggests that the smaller extent of the
MIMOSA dry core in the southern hemisphere polar vortex is more consistent with the MIPAS data.

Figure 3 highlights the differences in the vertical extent of the dry region of the southern hemisphere polar vortex, between the different analyses. Over the intercomparison period, the BASCOE moisture minimum has a greater vertical extent, reaching approximately $20 \mathrm{hPa}$, while for ECMWF and MIMOSA it only reaches approximately $30 \mathrm{hPa}$. Figure 11 describes how the specific humidity field varies over the South Pole at 12:00UT on the 21 September 2003 at $32 \mathrm{hPa}$, which is in this region of the upper limit of the dry vortex region. At this level, the BASCOE specific humidity values are less than $1.5 \mathrm{ppmv}$ in contrast to the 3 ppmv seen in MIMOSA and ECMWF. Dehydration over the vortex core, 

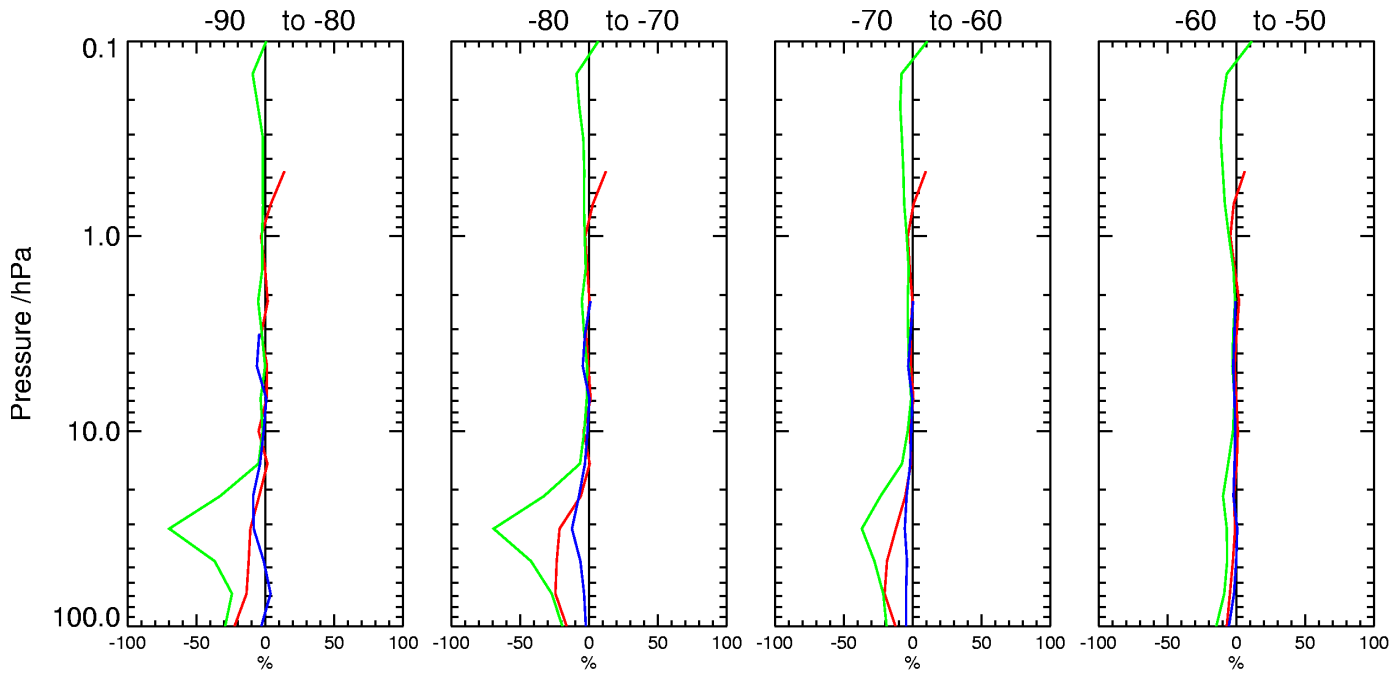

Fig. 7. Mean of (Analysis-MIPAS), normalised by climatology (in percent) over the intercomparison period, for ECMWF (Red), BASCOE (Green) and MIMOSA (Blue), concentrating on the southern high latitudes $\left(50^{\circ} \mathrm{S}\right.$ to $90^{\circ} \mathrm{S}$ in $10^{\circ}$ bands).
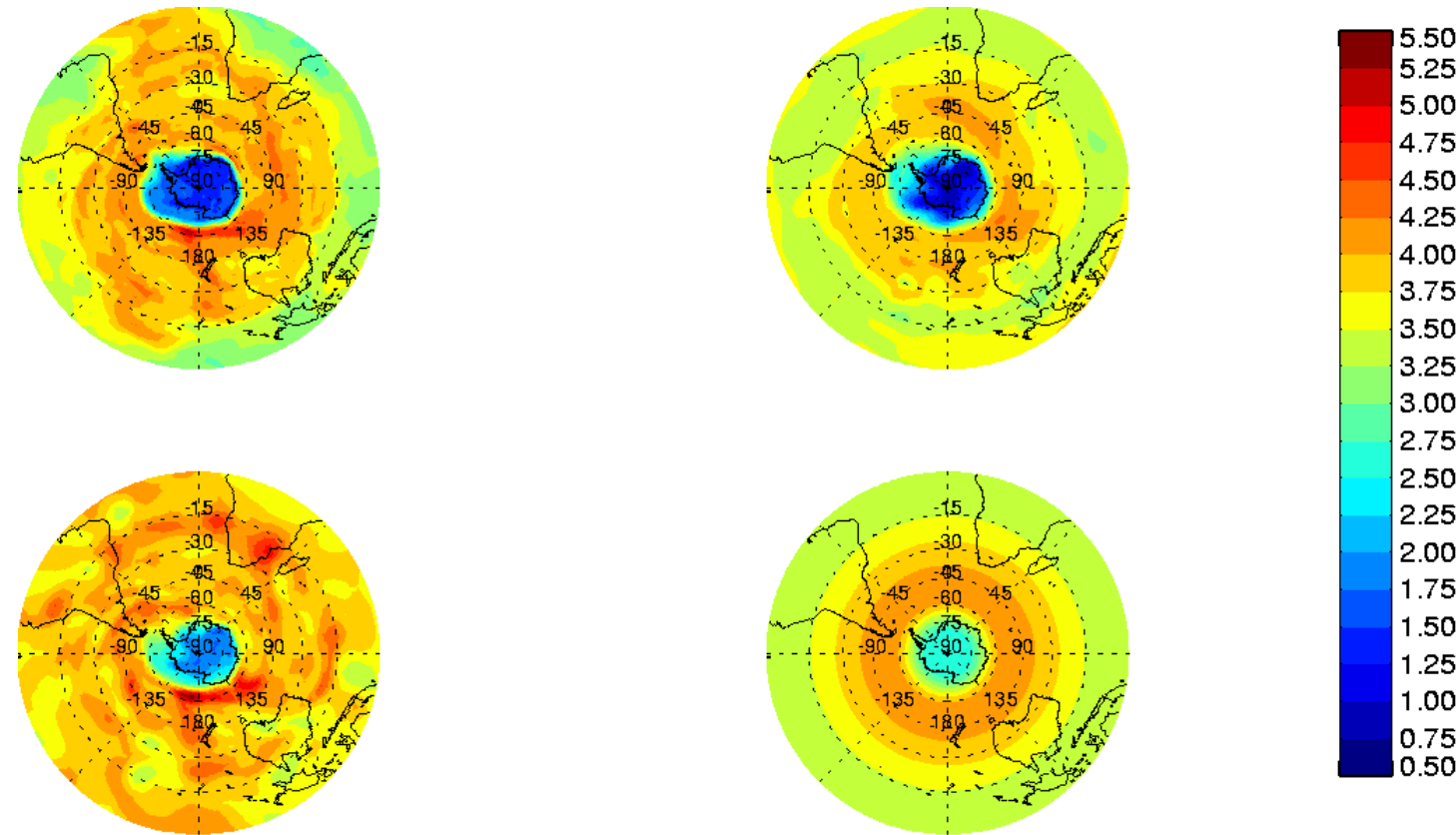

Fig. 8. Polar stereographic projection of the specific humidity field (ppmv) for the southern hemisphere on 21 September 2003 12:00 UT at $68 \mathrm{hPa}$, for ECMWF (top left), BASCOE (top right), MIMOSA (bottom left) and climatology (bottom right). 


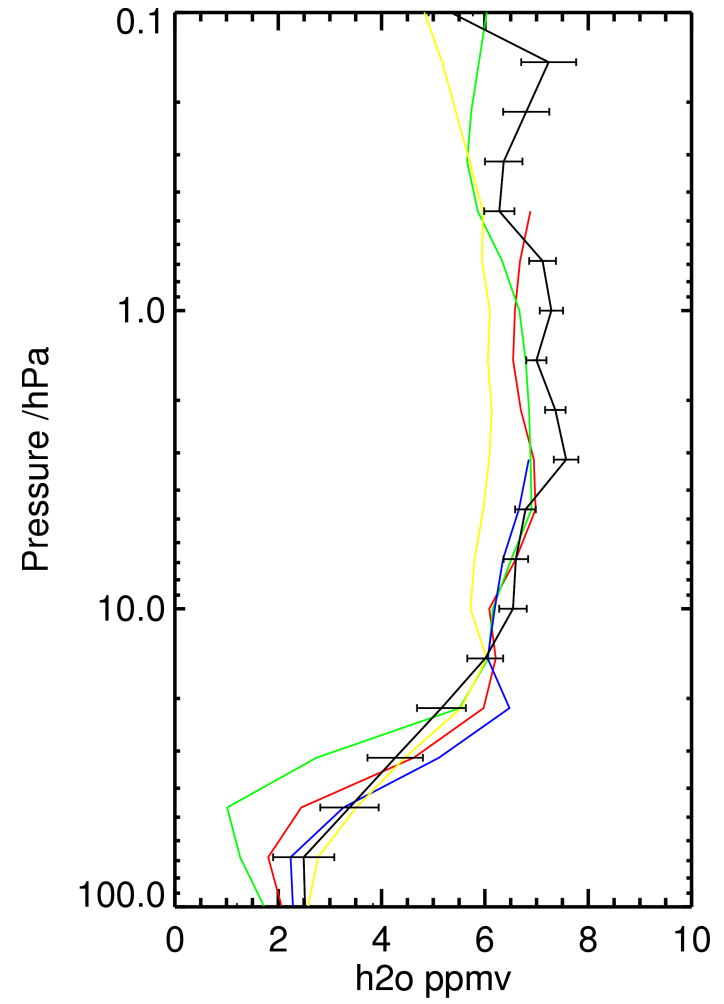

Fig. 9. A comparison of a MIPAS profile (black, with one standard deviation error bars - 21 September 2003, 10:13 a.m., $168^{\circ} \mathrm{W}$, $74^{\circ} \mathrm{S}$ ) with the different analyses and climatology (colours as Fig. 2).

associated with the cold polar temperatures, limits the presence of the descended moist upper stratospheric air to the outer rim of the vortex in the ECMWF and MIMOSA analyses. A comparison with MIPAS observations indicates that at approximately $30 \mathrm{hPa}$, the BASCOE analyses are too dry, with a bias of $70 \%$ (Fig. 7). A comparison with a single MIPAS profile (Fig. 9) shows that the gradient of increasing humidity with altitude in the BASCOE analysis between $40 \mathrm{hPa}$ and $10 \mathrm{hPa}$ is too steep and is displaced vertically upwards by approximately $10 \mathrm{hPa}$. This gradient in the MIMOSA and ECMWF analyses is also too steep, however the gradient is better located in the vertical.

As described previously, the peak in the biases with respect to independent observations in the southern hemisphere high latitudes occurs at $30-45 \mathrm{hPa}$. A comparison with a single POAM III profile (Fig. 10) also highlights the problematic transition zone above the vortex. In the BASCOE analysis, PSC sedimentation can still be seen to be very important at $32 \mathrm{hPa}$ (producing the very low humidity values), whereas according to the POAM and MIPAS data this may not be the case. As explained earlier, the BASCOE PSC sedimentation scheme appears to be overestimating the water vapour loss. This BASCOE dry bias may be further exacerbated by the low sulphate aerosol loading in 2003 (due to the last major volcanic eruption occurring in 1991), which would not have been captured in the BASCOE model. Sulphate aerosols are responsible for generating ice particles and consequently water vapour sedimentation (via NAT particles, Daerden et al., 2007), reduced aerosol loading therefore results in reduced drying. BASCOE is the only model to include a PSC parametrization and the results presented here highlight the complexity of attempting chemical assimilation with explicit chemistry models in comparison to tracer transport models. The peak in the biases at $30-45 \mathrm{hPa}$ in all three analyses therefore relate to the inability of the analyses to correctly capture the strong vertical humidity gradient above the southern hemisphere polar vortex.

\subsubsection{Upper stratosphere and lower mesosphere}

In the upper stratosphere (here used to refer to $20-1 \mathrm{hPa}$ ) there are two processes which affect the water vapour concentration and distribution, the production of water vapour by methane oxidation and the horizontal and vertical transport by the Brewer-Dobson circulation. Figures 5 and 6 show that the analyses compare very favourably with the MIPAS observations at these levels, with biases less than $5 \%$ and standard deviations less than $10 \%$, indicating the observations have been well assimilated. A comparison with independent data however shows that around $2-3 \mathrm{hPa}$ there is often a wet bias. This is particularly true with respect to HALOE data, where the analyses have a $20 \%$ wet bias over most of the upper stratosphere, peaking at $2 \mathrm{hPa}$. This contradiction may in part relate to the MIPAS wet bias relative to the HALOE data described in Sect. 3. However at selected latitudes, wet biases at this altitude also exist with respect to POAM III and SAGE II data, with peaks in the standard deviations of the analysis departures, and therefore the source of this bias deserves further investigation.

Figure 3 highlights that at the $2-3 \mathrm{hPa}$ the water vapour field is dominated by a strong latitudinal gradient. At higher latitudes, moist older air is found, which has descended from the upper stratosphere where longer exposure to methane oxidation has given the air a relatively wet signature. The younger, dry, low latitude air has risen from the lower stratosphere. The bias peaks are therefore highly likely to relate to the ability of the different analyses to represent this strong latitudinal gradient in water vapour. In the monthly mean water vapour analyses (Fig. 3) and through consideration of daily plots (not shown), BASCOE has a weaker northern hemisphere moist centre at $2 \mathrm{hPa}$. BASCOE is also found to have a slightly smaller wet bias when compared to HALOE and POAM III data in this region than ECMWF and therefore appears the more realistic representation. A similar feature is also found in the southern hemisphere mid latitudes. It is not possible to assess which of the southern hemisphere high latitude analyses are most realistic as the data comparisons vary greatly. MIMOSA has a very noisy daily water vapour field at $2 \mathrm{hPa}$, leading to a variety of biases and standard 
deviations. The patchy nature of the MIMOSA analyses will be discussed in Sect. 5.2.3. Between 1-2 hPa at most latitudes, there is a large dry bias of the analyses with respect to the SAGE II data, that is not seen when compared to the other observations. As discussed in Sect. 3, the SAGE II data is found to be noisy in this region and gives wetter readings than the other satellite data. The poor quality of the SAGE II data in this region is therefore likely to be responsible for the large biases seen.

In the lower mesosphere (pressures lower than $1 \mathrm{hPa}$ ), BASCOE and ECMWF analyses compare well with the assimilated MIPAS data, with biases of less than $10 \%$. Above $0.2 \mathrm{hPa}$, BASCOE has an increasing wet bias and standard deviation of analysis departures, however the proximity to the model top is expected to degrade the quality of the analyses. In comparison to independent data, the analyses are again reasonable with biases and standard deviations of less than $20 \%$ and $25 \%$ respectively. A higher percentage of MIPAS observations were rejected in the USLM by the BASCOE system compared to ECMWF (Table 2). This is especially true in the southern hemisphere high latitudes and again may indicate the poor quality of the observations or analyses near the model top.

\subsubsection{Spatial structure of the analyses}

Figures 4, 8 and 11 give a feel for the spatial coherence of the specific humidity fields generated by the different data assimilation schemes. These figures highlight that although the different analyses show similar large-scale water vapour features, there are considerable variations at the smaller scale; for example MIMOSA has a noisier water vapour field throughout the depth of the stratosphere. Differences in the assimilation schemes, grid resolutions and observation filtering criteria are likely responsible for these differences. The tracer like properties of water vapour in the stratosphere and lower mesosphere make the spatial variability in the MIMOSA analyses unrealistic. Unlike ECMWF and BASCOE, MIMOSA did not filter out any of the MIPAS observations and therefore, the poor quality of some of the profiles would pass through to the analyses. Another reason for the unrealistically noisy MIMOSA water vapour fields is likely due to the error correlations being related to PV. The PV field can be quite variable in space, especially in the mid latitudes. Even if a grid point that is relatively far from a MIPAS observation has a similar PV value as found at the observation location, it will be given a similar water vapour increment. The patchy structure of the analyses may also therefore reflect the patchy nature of the PV field. Consequently, although the MIMOSA analyses compare most favourably with the MIPAS observations, the smoother ECMWF and BASCOE stratospheric water vapour fields are closer to what one might expect from a water vapour field that is determined mainly by the large scale circulation, photochemistry and location specific dehydration (Kley et al., 2000). Further ob-

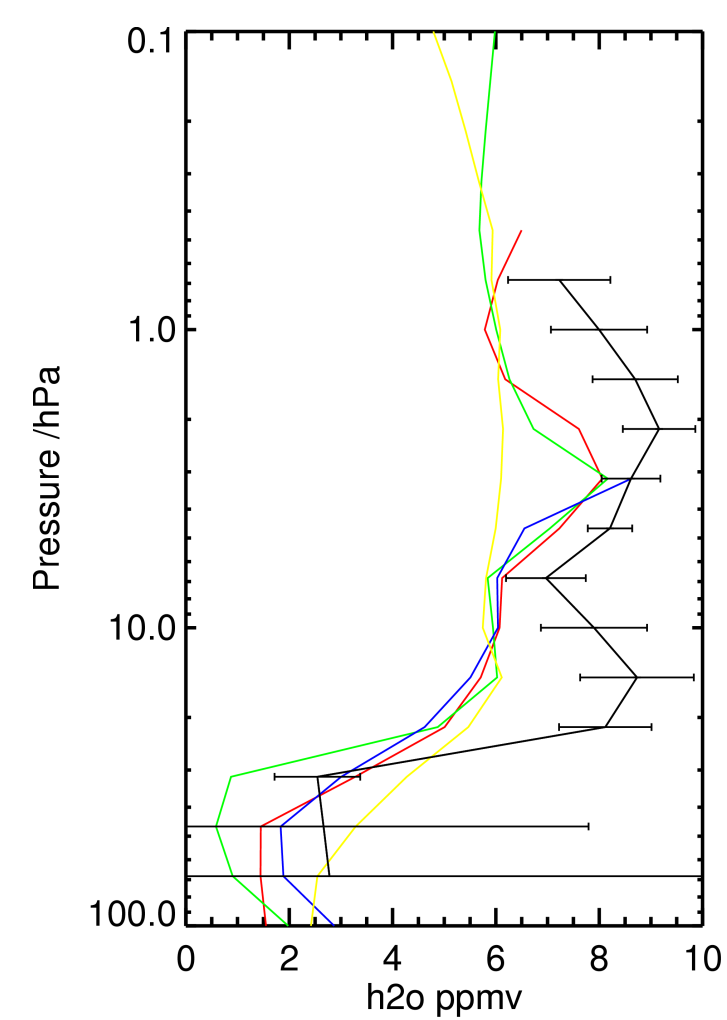

Fig. 10. A comparison of a POAM profile (black, with one standard deviation error bars - 21 September $2003,12: 00$ p.m., $283^{\circ}$ E, $88^{\circ} \mathrm{S}$ ) with the different analyses and climatology (colours as Fig. 2).

servations of the daily stratospheric water vapour field and detailed analysis of the MIPAS observations and MIMOSA analysis increments would be required to assess whether any part of the variability seen in the MIMOSA analyses has a physical justification. The BASCOE water vapour fields are particularly smooth and reflect its low horizontal grid resolution compared to the resolution of the MIPAS observations.

\section{Met Office analyses}

The Met Office also assimilated MIPAS water vapour profiles into their system over the intercomparison period, but these analyses have not been included in the intercomparison described in Sect. 5 due to their poor performance. We illustrate this here using analysis minus MIPAS percentage differences, and the standard deviation of this difference, for all latitudes (Fig. 12). The poor quality of the Met Office analyses compared to the others is very clear. At nearly all pressure levels, the Met Office analyses have a large dry bias compared to the MIPAS observations. In the lower stratosphere there is a dry bias of $20-40 \%$ and in the USLM, the dry bias increases with altitude, with the largest bias exceeding $50 \%$. The standard deviation of analysis departures is 

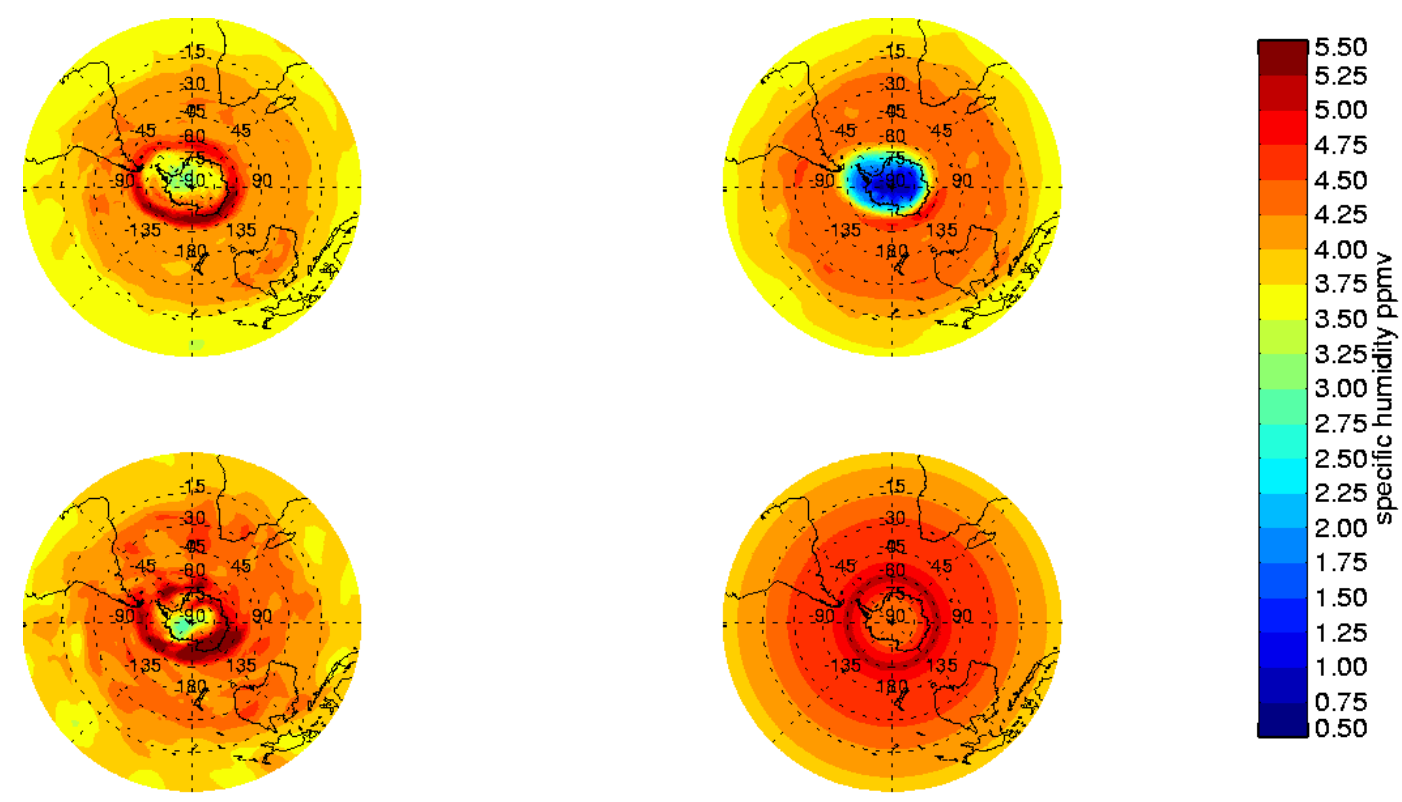

Fig. 11. Polar stereographic projection of the specific humidity field (ppmv) for the southern hemisphere on the 21 September 2003 12:00 UT at $32 \mathrm{hPa}$, for ECMWF (top left), BASCOE (top right), MIMOSA (bottom left) and climatology (bottom right).
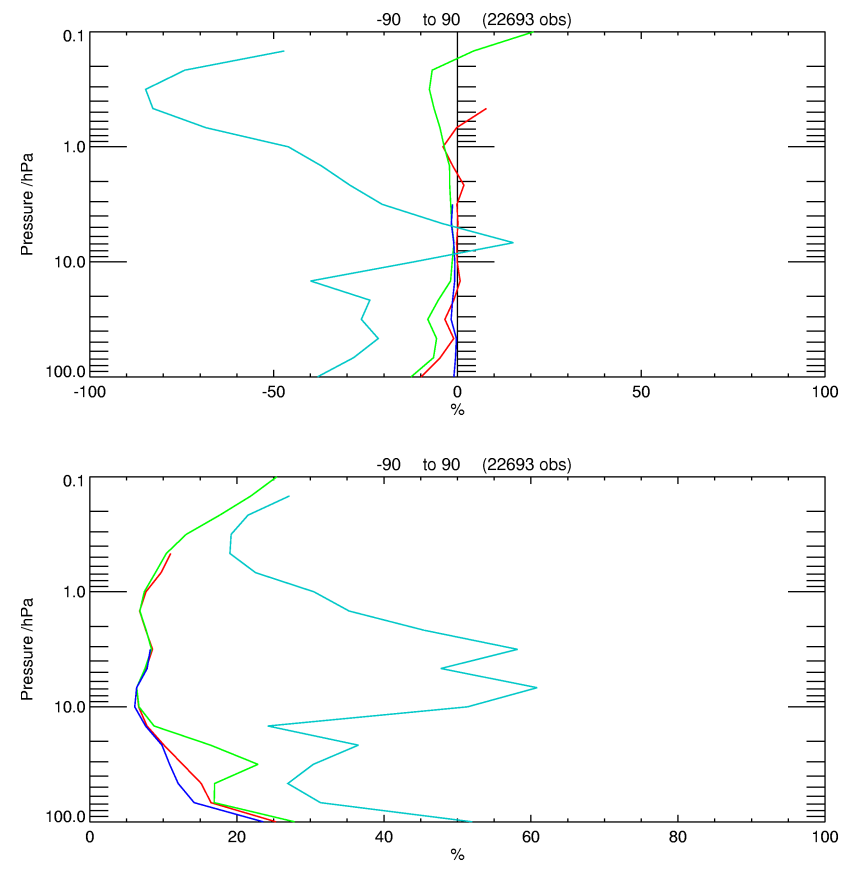

Fig. 12. Top: mean of (Analysis - MIPAS) water vapour mixing ratio, normalised by climatology (in percent) over the intercomparison period, for ECMWF (Red), BASCOE (Green), MIMOSA (Blue) and Met Office (light Blue), for all latitudes. Bottom: as top but standard deviation rather than mean difference. particularly large in the upper stratosphere, where it exceeds $50 \%$. These biases occur at all latitudes, but are worst in the high latitudes (not shown). Over the intercomparison period, only approximately $4 \%$ of MIPAS observations in the lower stratosphere were rejected by the Met Office quality control scheme. However, in the USLM 37\% of MIPAS observations were rejected, a much higher quantity than rejected by the other models, reflecting the model's poor background humidity field.

The Met Office assimilation system used in these experiments is as described in (Geer et al., 2006), but with a number of improvements to the forecast model. The model has 50 vertical levels ranging from the surface to $\sim 0.1 \mathrm{hPa}$ and a horizontal resolution of $3.75^{\circ}$ longitude by $2.5^{\circ}$ latitude. The model dynamical equations, including the transport scheme, have a semi-Lagrangian formulation (Davies et al., 2005), and the model also includes a parametrization of the production and loss of water vapour in the USLM by methane oxidation and photolysis. The data assimilation uses 3D-Var (Lorenc et al., 2002) with a 6-h assimilation window. The humidity control variable used is normalised specific humidity, as described by Hólm et al. (2002), and similar to that used by ECMWF. In addition, any correlation between temperature and specific humidity is removed from the control variable, following Dee and da Silva (2003). In these experiments the analysed specific humidity field is limited to between 0 ppmv and 12 ppmv, in order to ensure the continuity of the run. Without this pre-imposed limit, after a couple of weeks of assimilation, due to unrealistically large humidity analysis increments, the stratospheric water vapour field reached significantly higher values and resulted in the failure 
of the run. The limit of 12 ppmv was chosen to ensure that the experiment ran without failure but also to allow plenty of scope for more realistic humidity analysis increments to be retained by the system.

The Met Office bias with respect to the MIPAS observations shown in Fig. 12 can be seen after one 6-h assimilation window, when starting from a realistic background. It is therefore clear that these biases relate directly to the assimilation scheme and its resultant humidity increments, rather than the model dynamics or parametrizations. Many of the problems associated with the humidity assimilation may be linked to the specification of the background error covariances.

The background error covariances for the new humidity control variable were generated using the National Meteorological Centre (NMC) method (Parrish and Derber, 1992). In this method, model errors are assumed to be represented by the difference between forecasts of different length. The NMC error covariances used here were based on differences between a series of 24 and 48-h forecasts. These forecasts were generated from operational Met Office analyses. Such analyses do not include MIPAS observations and the resultant lack of water vapour observations in the stratosphere means that there is considerable doubt as to whether the NMC method can produce realistic error variances and vertical correlations for stratospheric water vapour. Support for this assertion comes from (Polavarapu et al., 2005a), who showed that use of NMC temperature covariances led to the production of unphysical temperature analyses above $1 \mathrm{hPa}$, where there are no temperature observations available to constrain the analyses.

Investigations into the characteristics of the NMC humidity covariances found that the error variances, at a particular level, often exceeded the background humidity value, and that the vertical correlations were unrealistically deep. For example, correlations were found between the boundary layer and the mesosphere, which means that a bias in the troposphere could therefore erroneously give rise to a bias in the mesosphere. Tools were developed at the Met Office to cut back both the error correlations and variances and tested using single observation experiments. Background error variances were cut down to $50 \%$ of their background humidity value, while vertical correlations deeper than $8 \mathrm{~km}$ were suppressed. The scaling tools were found to have some positive impact, removing many large inappropriate stratospheric humidity increments. The scaling tools could not however improve upon the profile signature seen in Fig. 12. Even after scaling of the covariance matrix, smaller scale, erroneous humidity increments were still added at every assimilation cycle.

An explanation for the persistence of these erroneous increments, even after scaling, is as follows. In the Met Office assimilation scheme, the background error covariance matrix is mathematically transformed prior to use, in order to remove all non-zero off-diagonal terms. Without such a trans- form, inversion of the background error covariance matrix would be computationally impossible. In the vertical, the error covariance matrix is transformed into orthogonal vertical modes, such that the errors are uncorrelated between modes. The vertical correlation scaling mentioned above is applied before the vertical mode calculation. However, if the vertical error correlations are reduced excessively, or non-smoothly with height, it is found that the vertical mode calculation can introduce other, probably spurious, deep vertical correlations. If weaker scaling is applied, spurious correlations are not introduced by the vertical mode calculation, but the scaling is too weak to adequately remove the strong, erroneous vertical correlations present in the original covariances calculated by the NMC method. Single observation tests show that, for a whole range of vertical correlation scalings used, the scaling approach proves unsuccessful in removing the erroneous deep correlations between the tropopause and the mesosphere.

A possible way forward is to reconsider the way in which the humidity background error covariance matrix is calculated, rather than to scale existing covariances, as we have attempted here. A recent study by Jackson et al. (2008), has shown that the 3D-Var analyses on which the NMC covariance calculation was based, suffer from a lack of dynamical balance between the mass and wind fields. Spurious gravity waves are generated to restore this balance and can be seen in a 24-h forecast and consequently are present in the NMC error covariance matrix. This may explain the unrealistic vertical correlations in the humidity covariance matrix reported here. Of course, the presence of a spurious gravity wave signal in the error covariances may have an adverse effect on all analysis variables, but this effect may be greatest for humidity because of the lack of suitable stratospheric humidity observations to constrain the analyses on which the NMC method is based.

Solutions to this problem include the use of betterbalanced analyses in the NMC calculation. For example, at the Met Office, 3D-Var analyses have recently been superseded by 4D-Var analyses, which are in much better dynamical balance and give rise to NMC covariances which contain a reduced spurious gravity wave signal. Other techniques of calculating error covariances may also be more effective at removing spurious gravity waves. Such techniques include the method described by Polavarapu et al. (2005b) (the so-called Canadian Quick covariances) and the use of ensembles. Ensembles are used to calculate background error covariances at ECMWF. This may explain why the ECMWF stratospheric humidity analyses presented here are much more accurate than the corresponding Met Office analyses, even though the humidity control variable used at both institutes is very similar. It is not easy to apply the ECMWF covariances to the Met Office DA scheme, due to the different model formulations, however the use of ensembles to generate covariances is being further developed at the Met Office. 


\section{Conclusions}

The availability of MIPAS specific humidity profiles has enabled modelling centres to test the reliability of their current humidity data assimilation schemes in the middle atmosphere. For a one-month period (29 August-29 September 2003), MIPAS water vapour profiles have been assimilated into four models, two global circulation models (ECMWF and Met Office) and two chemical transport models (BASCOE and MIMOSA). Although BASCOE and MIMOSA are both CTMs, they differ substantially in that BASCOE models most stratospheric chemistry constituents and has explicit chemistry, in contrast to MIMOSA. The resultant analyses were compared with the original MIPAS observations and with other independent water vapour data sources, HALOE, SAGE II and POAM III. To enable comparison, the different centres' analyses were interpolated onto a common grid, followed by interpolation to observation locations. The analyses minus observation statistics were latitudinally binned and the results presented as percentages, relative to a monthly mean UARS climatology. Met Office results are not considered alongside the other analyses due to their poor performance.

Comparison of the analyses with the independent data, has highlighted areas where the analyses are either realistic or still require further improvement. On the broad scale, the three analyses considered (BASCOE, MIMOSA and ECMWF) compare favourably with the UARS climatology. The main features of the stratospheric water vapour field are captured, such as the tropical water vapour minimum, the southern hemisphere polar vortex water vapour minimum and the vertical distribution of water vapour associated with the Brewer-Dobson circulation. In the mesosphere the analyses are wetter than the UARS climatology and reflect the wet bias of the MIPAS observations relative to other satellite data in this region.

The region of the stratosphere-lower mesosphere which the assimilation schemes find hardest to simulate, is the southern hemisphere polar vortex between $100 \mathrm{hPa}$ and $20 \mathrm{hPa}$. Most of the analyses struggle to correctly capture the moisture minimum within the vortex core and also the strong horizontal and vertical humidity gradients at the vortex boundary, resulting in large dry biases in this region. The water vapour minimum in the tropical lower stratosphere associated with previous temperature minima at the tropopause, and the horizontal transport of this dry air to higher latitudes is also difficult for the assimilation systems to represent, with most systems showing a dry bias. BASCOE was found to have a particularly large dry bias in the southern hemisphere polar vortex and is most likely explained by an overactive PSC parametrization scheme. The MIPAS observations were only able to have a limited effect as many were rejected due to their deviation from the erroneously dry background field.

In the upper stratosphere all three analyses have assimilated the MIPAS observations well, with small biases and standard deviations. Larger biases exist when compared to independent observations, especially HALOE data, which can in part be explained by the relatively large MIPAS bias relative to HALOE in this region. The strong latitudinal water vapour gradient at $2 \mathrm{hPa}$ associated with the BrewerDobson circulation does however produce a peak in the biases in the upper stratosphere. The MIPAS observations have also been well assimilated in the lower mesosphere and small biases are found against independent data below $0.5 \mathrm{hPa}$ for both ECMWF and BASCOE. However the use of MIPAS data above the model top led to a biased representation of the mesosphere at pressure levels above $0.5 \mathrm{hPa}$ in the ECMWF analyses. The BASCOE bias and standard deviation also increased near the model top.

Although MIMOSA often has smaller biases with respect to the MIPAS observations, the resultant analyses are unrealistically noisy. This most likely reflects the lack of data quality control and the error covariance dependence on PV. The water vapour analyses of ECMWF and BASCOE are smoother and the low horizontal resolution of the BASCOE grid amplifies this homogeneity.

The Met Office stratospheric water vapour analyses were poor, with large dry biases at most latitudes and altitudes relative to all observations types. Investigations have shown that the poor assimilation of MIPAS profiles relates to an unrealistic humidity background error covariance matrix, rather than to any dynamical feature of the model. The humidity background error covariances were found to have excessively deep vertical error correlations and error variances that were larger than the background humidity values. Modification of the error covariance matrix failed to sufficiently improve the assimilation capability.

Comparison of the quality of the different water vapour analyses against MIPAS data and the independent observations has highlighted the following. Firstly, the role of the error covariance matrix is crucial in producing a realistic middle atmosphere water vapour analysis. Both the choice of the control variable and the way the error covariances are generated influence the final analyses. Secondly, quality control of the observations assimilated can avoid poor observations degrading the analyses. Also careful use must be made of observations near the model boundaries. Lastly, the assimilation schemes compared have succeeded in producing reasonable middle atmosphere water vapour analyses, although the schemes struggle to accurately reproduce regions where strong humidity gradients exist.

In this paper only the realism of the broad scale features of the middle atmosphere water vapour field has been compared. A longer period of intercomparison would allow for a better comparison, as well as enabling the inter-seasonal and inter-annual variability of the middle atmosphere water vapour field to be better understood. The assimilation of stratospheric water vapour remains problematic for operational forecasting centres because of a lack of real-time observations, the large changes in magnitude through the 
atmosphere and the need to capture its important relationship with atmospheric dynamics. Work will continue to develop the most appropriate humidity control variable and the best method for generating and representing its associated background error covariances in the assimilation scheme.

Acknowledgements. The work described in this paper was funded by ASSET. ASSET is an EU-funded Framework V project (contract EVK2-CT-2002-00137). The International Space Science Institute (ISSI; http://www.issibern.ch) provided support for this work, including funds for ASSET project meetings. Q. Errera is supported by the Belgian Federal Science Policy in the framework of the BASCOE ProDEx (PEA 90125). W. Lahoz is supported by an internal project at NILU. Comments and assistance from E. Hólm are gratefully acknowledged.

Edited by: M. Van Roozendael

\section{References}

Andersson, E. and Järvinen, H.: Variational quality control, Q. J. Roy. Meteor. Soc., 125, 697-722, 1999.

Bormann, N., Healy, S. B., and Hamrud, M.: Assimilation of MIPAS limb radiances in the ECMWF system. II: Experiments with a 2-dimensional observation operator and comparison to retrieval assimilation, Q. J. Roy. Meteor. Soc., 133, 329-346, doi:10.1002/qj.47, 2007.

Brewer, A. W.: Evidence for a world circulation provided by the measurements of helium and water vapour distribution in the stratosphere, Q. J. Roy. Meteor. Soc., 75, 351-363, doi:10.1002/qj.49707532603, 1949.

Cohn, S. E.: Assessing the effects of data selection with the DAO physical-space statistical analysis system, Mon. Weather Rev., 126(2913), 2013-2926, 1998.

Daerden, F., Larsen, N., Chabrillat, S., Errera, Q., Bonjean, S., Fonteyn, D., Hoppel, K., and Fromm, M.: A 3D-CTM with detailed online PSC-microphysics: analysis of the Antarctic winter 2003 by comparison with satellite observations, Atmos. Chem. Phys., 7, 1755-1772, 2007,

http://www.atmos-chem-phys.net/7/1755/2007/.

Davies, T., M. J. P. Cullen, Malcolm, A. J., Mawson, M. H., Staniforth, A., White, A. A., and Wood, N.: A new dynamical core for the Met Office's global and regional modelling of the atmosphere, Q. J. Roy. Meteor. Soc., 131, 1759-1782, 2005.

Errera, Q., Daerden, F., Chabrillat, S., Lambert, J. C., Lahoz, W. A., Viscardy, S., Bonjean, S., and Fonteyn, D.: 4D-Var assimilation of MIPAS chemical observations: ozone and nitrogen dioxide analyses, Atmos. Chem. Phys., 8, 6169-6187, 2008, http://www.atmos-chem-phys.net/8/6169/2008/.

Dee, D. and da Silva, A.: The Choice of Variable for Atmospheric Moisture Analysis, Mon. Weather Rev., 131, 155-171, 2003.

El Amraoui, L., Ricaud, P., Urban, J., Théodore, B., Hauchecorne, A., Lautié, N., De La Noë, J., Guirlet, M., Flochmoën, E. L., Murtagh, D., Dupuy, E., Frisk, U., and Fanton d'Andon, O.: Assimilation of Odin/SMR $\mathrm{O}_{3}$ and $\mathrm{N}_{2} \mathrm{O}$ measurements in a threedimensional chemistry transport model, J. Geophys. Res., 109, D22304, doi:10.1029/2004JD004796, 2004.
Fierli, F., Hauchecorne, A., Bekki, S., Théodore, B., and Fanton d'Andon, O.: Data assimilation of stratospheric ozone using a high-resolution transport model, Geophys. Res. Lett., 29, 1381, doi:10.1029/2001GL014272, 2002.

Fischer, H. and Oelhaf, H.: Remote sensing of vertical profiles of atmospheric trace constituents with MIPAS limb-emission spectrometers, Appl. Optics, 35, 2787-2796, 1996.

Fisher, M.: Background error covariance modelling, in: Seminar on Recent developments in data assimilation for atmosphere and ocean, 8-12 September 2003, edited by ECMWF, Shinfield Park, Reading, 45-64, 2003.

Geer, A. J., Lahoz, W. A., Bekki, S., Bormann, N., Errera, Q., Eskes, H. J., Fonteyn, D., Jackson, D. R., Juckes, M. N., Massart, S., Peuch, V.-H., Rharmili, S., and Segers, A.: The ASSET intercomparison of ozone analyses: method and first results, Atmos. Chem. Phys., 6, 5445-5474, 2006,

http://www.atmos-chem-phys.net/6/5445/2006/.

Harries, J. E., Russell III, J. M., Tuck, A. F., Gordley, L. L., Purcell, P., Stone, K., Bevilacqua, R. M., Gunson, M., Nedoluha, G., and Traub, W. A.: Validation of measurements of water vapor from the Halogen Occultation Experiment (HALOE), J. Geophys. Res, 101, 10 205-10 216, 1996.

Healy, S. B. and Thépaut, J. N.: Assimilation experiments with CHAMP GPS radio occultation measurements, Q. J. Roy. Meteor. Soc., 132, 605-623, 2006.

Hólm, E., Andersson, E., Beljaars, A., and et al.: Assimilation and Modelling of the Hydrological Cycle: ECMWF2̆019s Status and Plans, Tech. Memo., 383, ECMWF, 2002.

Jackson, D. R., Burrage, M. D., Harries, J. E., Gray, L. J., Russell, J. M.: The semi-annual oscillation in upper stratospheric and mesospheric water vapour as observed by HALOE, Q. J. Roy. Meteor. Soc., 124, 2493-2515, 1998.

Jackson, D. R., Keil, M., and Devenish, B. J.: Use of Canadian Quick Covariances in the Met Office data assimilation system, Q. J. Roy. Meteorol. Soc., 134, 1567-1582, 2008.

Juckes, M. N.: An annual cycle of long lived stratospheric gases from MIPAS, Atm. Chem. Phys., 7, 1879-1897, 2007.

Kalnay, E.: Atmospheric modeling, data assimilation and predictability, Cambridge University Press, UK, 2003.

Kley, D., Henderson, E. J. S. W. R., Drummond, J. R., Harrop, W. J., Schmeltekopf, A. L., Thompson, R. L., and Winkler, R. H.: In situ measurements of the mixing ratio of water vapor in the stratosphere, J. Atmos. Sci., 36, 2513-2524, 1979.

Kley, D., Russell III, J. M., and Phillips, C.: SPARC assessment of upper tropospheric and stratospheric water vapour, Tech. Rep. 2, SPARC, WMO, Geneva, 2000.

Lahoz, W. A., Geer, A. J., and O'Neill, A.: Dynamical evolution of the 2003 southern hemisphere stratospheric winter using Envisat trace-gas observations, Q. J. Roy. Meteor. Soc., 132, 1985-2008, doi:10.1256/qj.05.221, 2006.

Lahoz, W. A., Errera, Q., Swinbank, R., and Fonteyn, D.: Data assimilation of stratospheric constituents: a review, Atmos. Chem. Phys., 7, 5745-5773, 2007,

http://www.atmos-chem-phys.net/7/5745/2007/.

Lorenc, A. C., Ballard, S. P., Bell, R. S., and et al.: The Met Office global three dimensional data assimilation scheme, Q. J. Roy. Meteor. Soc., 126, 2991-3012, 2002.

Lumpe, J., Bevilacqua, R., Randall, C., Nedoluha, G., Hoppel, K., Russell, J., Harvey, V. L., Schiller, C., Sen, B., Taha, G., Toon, 
G., and Vömel, H.: Validation of Polar Ozone and Aerosol Measurement (POAM) III version 4 stratospheric water vapor, J. Geophys. Res., 111, doi:10.1029/2005JD006763, 2006.

Mastenbrook, H. J. and Daniels, R. E.: Atmospheric Water Vapor, chap. Measurements of stratospheric water vapor using a frost point hygrometer, Academic Press, 1980.

Mauldin III, L. E., Zaun, N. H., McCormick, M. P., Guy, J. H., and Vaughn, W. R.: Stratospheric aerosol and gas experiment II instrument: a functional description, Opt. Eng., 24, 307-312, 1985.

Ménard, R. and Chang, L.-P.: Assimilation of stratospheric chemical tracer observation using Kalman filter. Part II: $\chi^{2}-$ Validated results and analysis of variance and correlation dynamics, Mon. Weather Rev., 128, 2672-2686, 2000.

Mote, P. W., Rosenlof, K. H., McIntyre, M. E., Carr, E. S., Gille, J. C., Holton, J. R., Kinnersley, J. S., Pumphrey, H. C., Russell, III, J. M., and Waters, J. W.: An atmospheric tape recorder: The imprint of tropical tropopause temperatures on stratospheric water vapor, J. Geophys. Res., 101, 3989-4006, doi:10.1029/95JD03422, 1996.

Oelhaf, H., Fix, A., Schiller, C., and et al.: Validation of MIPAS ENVISAT v4.61 operational data with balloon and aircraft measurements: $\mathrm{H}_{2} \mathrm{O}$, in: ESA Special Publication SP-572: Second Workshop on the Atmospheric Chemistry Validation of ENVISAT (ACVE-2), 2004.

Pappalardo, G., Colavitto, T., Congeduti, F., et al.: Validation of MIPAS water vapor products by ground based measurements, in: ESA Special Publication SP-572: Second Workshop on the Atmospheric Chemistry Validation of ENVISAT (ACVE-2), 2004.

Parrish, D. F. and Derber, J. C.: The National Meteorological Center's spectral statistical-interpolation analysis system, Mon. Weather Rev., 120, 1747-1763, 1992.

Polavarapu, S., Shepherd, T. G., Rochon, Y., and Ren, S.: Some challenges of middle atmosphere data assimilation, Q. J. Roy. Meteor. Soc., 131, 3513-3527, 2005 a.

Polavarapu, S., Ren, S., Rochon, Y., Sankey, D., Ek, N., Koshyk, J., and Tarasick, D.: Data assimilation with the Canadian Middle Atmosphere Model, Atmos. Ocean, 43, 77-100, 2005 b.

Pumphrey, H. C., Rind, D., M., J., Russell III, and Harries, J. E.: A preliminary zonal mean climatology of water vapour in the stratosphere and mesosphere, Adv. Space Res., 21, 1417-1420, 1998.
Rabier, F., Jarvinen, H., Klinker, E., Mahfouf, J. F., and Simmons, A.: The ECMWF operational implementation of fourdimensional variational assimilation. I: Experimental results with simplified physics, Q. J. Roy. Meteor. Soc., 126, 1148-1170, 2000.

Raspollini, P., Belotti, C., Burgess, A., Carli, B., Carlotti, M., Ceccherini, S., Dinelli, B. M., Dudhia, A., Flaud, J.-M., Funke, B., Höpfner, M., Lopez-Puertas, M., Payne, V., Piccolo, C., Remedios, J. J., Ridolfi, M., and Spang, R.: MIPAS level 2 operational analysis, Atmos. Chem. Phys., 6, 5605-5630, 2006, http://www.atmos-chem-phys.net/6/5605/2006/.

Russell III, J. M., Gordley, L. L., Park, J. H., Drayson, S. R., Hesketh, D. H., Cicerone, R. J., Tuck, A. F., Frederick, J. E., Harries, J. E., and Crutzen, P. J.: The Halogen Occultation Experiment, J. Geophys. Res., 10777-10 797, 1993.

Schmidlin, F. and Ivanov, A.: Radiosonde relative humidity sensor performance: The WMO intercomparison2014Sept 1995, Preprints, 10th Symp. on Meteorological Observations and Instrumentation, Phoenix, AZ, Amer. Meteor. Soc., 68-71, 1998.

Simmons, A. J., Untch, A., Jakob, C., Kållberg, P., and Undén, P.: Stratospheric water vapour and tropical tropopause temperatures in ECMWF analyses and multi-year simulations, Q. J. Roy. Meteorol. Soc., 125, 353-386, doi:10.1256/smsqj.55316, 1999.

Solomon, S. and Brasseur, G.: Polar Ozone, in: The stratosphere and its role in the climate system, edited by: Brasseur, G. P., Springer-Verlag, 253-259, 1997.

Taha, G., Thomason, L. W., and Burton, S. P.: Comparison of Stratospheric Aerosol and Gas Experiment (SAGE) II version 6.2 water vapour with balloon-borne and space-based instruments, J. Geophys. Res., 109, D18313, doi:10.1029/2004JD004859, 2004.

Thomason, L. W., Burton, S. P., Iyer, N., Zawodny, J. M., and Anderson, J.: A revised water vapor product for the Stratospheric Aerosol and Gas Experiment (SAGE) II version 6.2 data set, J. Geophys. Res., 109, D06312, doi:10.1029/2003JD004465, 2004.

Weber, M., Bracher, A., Bramstedt, K., and et al.: Overview on validation of MIPAS H2O vapour by comparison with independent satellite measurements, in: ESA Special Publication SP572: Second Workshop on the Atmospheric Chemistry Validation of ENVISAT (ACVE-2), 2004. 